\title{
Las colocaciones usustantivo + de + sustantivon y su ubicación en el lexicón mental de una muestra de hablantes de E/LE
}

\author{
The collocations unoun + preposition de + noun» and their location \\ in the mental lexicon of a sample of S/FL speakers
}

Letizia D'Andrea

Universidad de Salamanca, España

\begin{abstract}
Resumen: Las colocaciones «sustantivo + de + sustantivo» representan un patrón muy productivo en español; sin embargo, suelen ocupar un lugar marginal en la enseñanza del español como lengua extranjera (E/LE) debido a su específica naturaleza referencial. De hecho, se usan tanto para cuantificar porciones de un todo (diente de ajo) como para designar conjuntos de entidades animadas o inanimadas que pertenecen a una misma categoría (bandada de aves, racimo de uvas). Por tanto, en este artículo nos proponemos ofrecer un análisis sintáctico y semántico de este tipo de colocaciones y averiguar qué conocimiento tiene de ellas una muestra de 15 hablantes de E/LE de niveles intermedios y avanzados.
\end{abstract}

Palabras clave: colocaciones, «sustantivo + de + sustantivo», fraseología, E/LE.

Abstract: The collocations «noun + preposition de + noun» are considerably productive in Spanish; however, they usually occupy a marginal place in the teaching of Spanish as a foreign language (S/FL) due to their specific referential nature. Indeed, they are used both to quantify portions of a whole, such as diente de ajo (clove of garlic) and to refer to groups of animated or unanimated entities belonging to the same category, such as bandada de pájaros and racimo de uvas (flock of birds and bunch of grapes, respectively). Therefore, this article aims to offer a syntactic and semantic analysis of this type of collocation and to assess their usage in a sample of 15 intermediate and advanced S/FL speakers.

Keywords: collocations, unoun + preposition de + noun», phraseology, Spanish as a foreign language.

\section{Introducción}

Hoy en día el interés por las colocaciones léxicas ha alcanzado cimas hace tiempo insospechadas. Cuando en 1957 el lingüista inglés John Firth dio a conocer el término collocation, con el fin de definir palabras que aparecen frecuentemente junto con otras, no fueron pocos los cabos que dejó sueltos (Evert, 2008: 1212-1213); su concepción demasiado amplia del fenómeno colocacional también incluía combinaciones libres de unidades léxicas. Años más tarde, los que se conocerían como neofirthianos (Halliday 1966b y Sinclair 1966, entre otros) fueron perfilando una definición más esmerada del concepto de colocación; y gracias a Sinclair (1966) estas ganaron terreno en la lexicografía computacional (Evert, 2008: 1213). Sin embargo, hubo que esperar hasta los años 80 del siglo pasado -en concreto, con 
los estudios de Haussmann (1985, 1988, 1989)- para que el fenómeno colocacional pudiera contar con una descripción aún más detallada (Bartsch, 2004: 36).

En la actualidad las colocaciones reciben cada vez más atención en los estudios académicos de corte didáctico; no obstante, aún no gozan de mucha consideración en gran parte de los manuales destinados al aprendizaje del español como lengua extranjera (de ahora en adelante, E/LE) ni en el aula misma. Como consecuencia de ello, muchos estudiantes de E/LE, incluso los de niveles intermedios y avanzados, tienden a crear combinaciones léxicas no registradas en la lengua, por ejemplo, traduciendo literalmente una determinada colocación de su lengua materna al español.

Por tanto, en esta investigación nos proponemos dos objetivos; por un lado, analizar semántica y sintácticamente el patrón colocacional que ha recibido menos atención en el ámbito de la fraseología: las colocaciones «sustantivo + de + sustantivo» (una loncha de jamón, una bandada de pájaros); y, por otro lado, averiguar qué conocimiento tiene de ellas una muestra de 15 hablantes de E/LE de niveles intermedios y avanzados que ha tomado cursos de español en el instituto, en la universidad o en academias de lenguas.

\section{Las colocaciones}

A pesar de los numerosos estudios sobre fraseología, las colocaciones son las unidades fraseológicas que han planteado más problemas de clasificación debido a los límites, a veces borrosos, que se interponen entre ellas y otros tipos de combinaciones léxicas, como las combinaciones libres (comer pan) -que, sin embargo, no constituyen unidades fraseológicas-y las locuciones (como tomar el pelo, en la acepción de 'burlarse de alguien').

Siguiendo la definición de Corpas Pastor (1996: 53), con colocaciones entendemos "sintagmas completamente libres, generados a partir de reglas, pero que, al mismo tiempo, presentan cierto grado de restricción combinatoria determinada por el uso". Se trata, por tanto, de combinaciones preferentes de unidades léxicas que disponen de un abanico limitado de colocados; por lo que cualquier 'infracción combinatoria', si bien sintáctica y gramaticalmente correcta, resultaría poco natural al oído del interlocutor ${ }^{\text {. }}$.

Entre los rasgos característicos de las colocaciones trataremos aquí el semántico y el sintáctico. En lo que atañe al nivel semántico, a diferencia de lo que ocurre con las unidades fraseológicas idiomáticas, el significado global de una colocación se desprende de la suma de los significados (rectos o metafóricos) de las unidades léxicas que la componen; de ahí que existan colocaciones rectas (o de significado composicional), como cepillarse los dientes, y colocaciones metafóricas (o de significado semicomposicional), como correr un rumor, donde el verbo correr presenta el significado metafórico de 'difundirse, esparcirse'.

\footnotetext{
1 Cada colocación se compone de dos unidades léxicas fuertes, los colocados, que, a su vez, se distinguen entre base y colocativo. La base es el elemento léxico que ejerce más fuerza, puesto que es el que determina cuáles son las unidades léxicas con las que puede combinarse. En las colocaciones "sustantivo + de + sustantivo» (diente de ajo o bandada de pájaros) el colocativo es el primer sustantivo (diente y bandada) y la base la constituye el segundo sustantivo (ajo y pájaros).
} 
Por otra parte, el aspecto sintáctico atañe a la restricción combinatoria de los componentes de una colocación, la base y el colocativo. Como sabemos, las posibilidades de combinar determinadas unidades léxicas no dependen únicamente de la libertad del hablante, sino que están supeditadas a restricciones léxicas establecidas en la norma. A pesar de ello, este grado de libertad combinatoria varía según la unidad léxica y la unidad de significado que queramos designar; de ahí que existan unidades léxicas que presentan un abanico más amplio de colocados y otras que solo admiten uno o más de un colocado, razón por la cual presentan un grado de fijación más elevado que las primeras. Como veremos más adelante, gran parte de las colocaciones objeto de estudio pertenece a este segundo grupo.

En la siguiente tabla mostramos los esquemas sintácticos más frecuentes en los que se dividen las colocaciones:

\begin{tabular}{|c|c|}
\hline ESQUEMA COLOCACIONAL & EJEMPLO \\
\hline Verbo + sustantivo (sujeto) & Correr un rumor \\
\hline Verbo + sustantivo (objeto) & Guardar un secreto \\
\hline Sustantivo + adjetivo & Error garrafal \\
\hline Adjetivo + sustantivo & Tímido intento \\
\hline Sustantivo + prep. de + sustantivo & Loncha de jamón \\
\hline Adverbio + adjetivo & Diametralmente opuesto \\
\hline Verbo + adverbio & Desear fervientemente \\
\hline
\end{tabular}

Tabla 1. Esquemas colocacionales más productivos

\subsection{Las colocaciones usustantivo + de + sustantivo"}

Las colocaciones «sustantivo + de + sustantivo» desempeñan la función de delimitar la cantidad del referente que seleccionan; no es ninguna casualidad que se combinen a partir de los que Bosque (1999: 18) denomina sustantivos acotadores (grano en un grano de uva) y sustantivos de grupo (racimo en racimo de uvas). Estos, junto con los llamados sustantivos de medida (como kilo en un kilo de uvas), constituyen una clase más amplia de sustantivos, los cuantificativos. Sin embargo, si los sustantivos acotadores y de grupo, al establecer relaciones preferenciales con un número limitado de unidades léxicas, pueden dar lugar a colocaciones, los sustantivos de medida (como kilo, litro, metro, etc.) forman únicamente combinaciones libres, puesto que la naturaleza referencial de esta subclase de cuantificativos les permite delimitar cualquier referente que posea los rasgos extralingüísticos sobre los que están llamados a cuantificar: litro delimita referentes líquidos, kilo sólidos y metro referentes que se extienden en longitud.

Las colocaciones "sustantivo + de + sustantivo» (una rebanada de pan, una jauría de perros), junto con algunas de las combinaciones libres que presentan el mismo esquema sintáctico (un grupo de turistas), forman las llamadas construcciones 
pseudopartitivas. Estas, al igual que las partitivas (del tipo gran parte de los invitados, la mayoría de la gente) sirven para hacer referencia a una parte de un todo. La parte es expresada por el primer sustantivo (por ejemplo, rebanada), y el todo -o la unidad entera- es expresado por el segundo sustantivo (pan). Desde el punto de vista sintáctico, a diferencia de las partitivas, el segundo sustantivo es escueto, es decir, no es precedido por ningún determinante².

\subsubsection{Los sustantivos acotadores}

Con acotadores nos referimos a los sustantivos "que denotan porciones de materia, es decir, a los nombres que toman sustantivos de materia como complemento y denotan una magnitud acotada o seleccionada" (Bosque, 1999: 18), como diente en un diente de ajo, rebanada en una rebanada de pan o gajo en un gajo de naranja.

Al igual que ocurre con otras clases de unidades fraseológicas, las unidades léxicas que componen estas colocaciones no siempre son recíprocas con las de otros idiomas. De hecho, si en español con el sustantivo acotador grano podemos delimitar una unidad de uva, de café o de arena, en otros idiomas no nos valdrá un único sustantivo para acotar los mismos referentes; así que, por ejemplo, en inglés tendremos a grape (una uva, con el artículo indefinido como elemento acotador), a bean of coffee, a grain of sand y en italiano un chicco d'uva, un chicco di caffé, pero un granello di sabbia, respectivamente. De todas formas, a pesar de las asimetrías con los patrones colocacionales de otros idiomas, sí es posible apreciar cierta sistematicidad combinatoria entre los sustantivos acotadores y los sustantivos que estos seleccionan, puesto que "existe en muchos casos cierta relación entre la forma o la consistencia del segmento acotado y la materia de la que se obtiene" (NGLE, 2004: 829); ejemplos de ello son colocaciones como loncha de jamón o loncha de queso, en las que loncha presenta el significado de "porción ancha y poco gruesa de algo, especialmente un alimento, que se corta o separa de la pieza entera o de una porción mayor" (DLE); con lo cual la elección del sustantivo que loncha delimita no es arbitraria, sino que depende de las características del referente al que dicho sustantivo remite: un alimento blando susceptible de ser cortado con una herramienta dotada de cuchilla3 ${ }^{3}$.

Cabe añadir que algunos de los sustantivos que pueden ser seleccionados por loncha también admiten los sustantivos trozo y pedazo. Sin embargo, la forma de la porción acotada será diferente; por lo que con trozo de queso o pedazo de jamón estaremos delimitando una porción irregular no necesariamente delgada ${ }^{4}$. Tal vez el

\footnotetext{
${ }^{2}$ Cabe señalar que, si bien estudiosos de fraseología como Corpas Pastor (1996: 74) y Koike (2001: 5052), entre otros, consideran este tipo de combinaciones léxicas colocaciones, García-Page (2008: 104) las adscribe a la clase genérica de sintagmas, en concreto, «N + prep. + N». Bosque (1999: 25), en cambio, al referirse a la selección semántica que ejercen los acotadores y los cuantificativos de grupo sobre determinados sustantivos, habla de restricciones léxicas; en ningún caso menciona el término colocación.

3 Loncha es un sustantivo acotador muy productivo en el español peninsular y en otras variedades diatópicas del español; sin embargo, como veremos en el apartado 4.1.2., su uso no se extiende a todas las variedades.

${ }^{4}$ Si bien existen sustantivos acotadores específicos para determinadas unidades léxicas, esto es, que seleccionan solo una o algunas de ellas, hay otros, como pedazo, trozo, porción, que, en palabras de Bosque (1999: 20) "actúan en cierta forma como comodines, puesto que su significado se ajusta exactamente al de «elemento acotador»". Por esta misma razón, al no formar combinaciones
} 
ejemplo más claro de la diferencia que hay entre una loncha y un trozo o pedazo de alimento lo encontramos en el referente pan; como bien sabemos, con loncha de pan nos referimos a una porción fina cortada a lo largo del diámetro de una hogaza o de una barra de pan mediante un cuchillo o una cortadora de pan, mientras que con trozo o pedazo de pan indicamos una porción más pequeña, y a la vez más gruesa, de pan que se separa de la pieza entera de forma irregular, por ejemplo, con las manos.

Otro sustantivo acotador que remite a la forma del referente seleccionado es rodaja, con el que, en la acepción que nos interesa, hacemos referencia a una "tajada circular o rueda de algunos alimentos" (DLE). Al igual que ocurre con loncha, la forma de la porción cortada se ajusta a la del diámetro del elemento acotado; de hecho, las cebollas, las patatas y los calabacines, entre otros alimentos, tienen forma ovalada, redonda y cilíndrica, respectivamente; razón por la cual, si se cortan siguiendo su diámetro, las tajadas tendrán una forma circular, como la de una rueda; de ahí el sustantivo rodaja.

Ahora bien, los sustantivos loncha y rodaja remiten a porciones de alimentos cortadas artificialmente mediante una herramienta específica (un cuchillo, una cortadora de embutidos, etc.); sin embargo, hay alimentos que presentan por naturaleza diferentes porciones, o bien porque están diseccionados en fragmentos más pequeños (como el ajo o la naranja), o bien porque están formados por distintas unidades (como la uva). De ahí que, para mencionar estas porciones, necesitemos otros sustantivos acotadores, un diente de ajo, un gajo de naranja y un grano de uva, respectivamente. Al igual que ocurre con otros sustantivos, ajo, naranja y uva pueden ser seleccionados por otros sustantivos acotadores, distinguiendo así el corte o unidad naturales del corte artificial; por lo que podemos decir gajo de naranja, pero también rodaja de naranja. En este último caso la porción cortada será más fina que la del gajo y se extenderá por una parte o por toda la superficie del cítrico5.

En lo que respecta a las colocaciones que se combinan a partir de un sustantivo acotador específico, cabe destacar el hecho de que estos pueden presentar significado metafórico, como ocurre en diente de ajo. En esta colocación el significado metafórico del acotador se establece a partir del parecido entre la forma que presenta la porción acotada y el referente que ha sido empleado para nombrarla, los dientes humanos o animales. De todos modos, a pesar del significado metafórico del acotador, la colocación no es idiomática, no solo porque el referente al que restringe presenta significado recto, sino también porque remite a un referente concreto.

Por último, como señala Bosque (1999: 20), los sustantivos acotadores permiten convertir en contables sustantivos no contables, ya que estos últimos "no pueden denotar "porciones de materia»" de por sí, como ocurre con sal o azúcar. De hecho, si queremos cuantificar una porción de sal para sazonar un plato o una de

preferenciales con los sustantivos que seleccionan, consideramos que los acotadores de significado genérico no dan lugar a colocaciones.

${ }_{5}$ Nótese que también decimos cortar en rodajas; por lo que, por ejemplo, si cortamos un diente de ajo en rodajas obtendremos unas rodajas o rodajitas de ajo. 
azúcar para el café, diremos una pizca de sal y un terrón de azúcar, respectivamenté

A continuación, recopilamos una lista de algunos de los sustantivos acotadores más utilizados en el español peninsular junto con los sustantivos concretos que seleccionan. La selección de los sustantivos se ha llevado a cabo a través de la consulta del Corpus del Español del Siglo XXI (CORPES XXI) de la Real Academia Española y del Diccionario combinatorio práctico del español dirigido por Ignacio Bosque.

\begin{tabular}{|l|l|l|}
\hline S. ACOTADOR & DE & S. ACOTADO(S) \\
\hline Aro & de & cebolla \\
\hline Brizna & de & aire, hierba, luz, paja, polvo... \\
\hline Chorro & de & aceite, agua, lejía, sangre, vinagre, vino, voz... \\
\hline Copo & de & avena, nieve \\
\hline Diente & de & ajo \\
\hline Gajo & de & limón, mandarina, naranja... \\
\hline Gota & de & agua, sangre, sudor... \\
\hline Grano & de & arena, arroz, cacao, café, maíz, sal, uva.... \\
\hline Hebra & de & hilo \\
\hline Hilo & de & agua, sangre, voz... \\
\hline Loncha & de & carne, jamón, pan, queso, salmón... \\
\hline Mota & de & polvo \\
\hline Rebanada & de & bizcocho, pan, tarta... \\
\hline Pellizco & de & azúcar, canela, pimienta, sal... \\
\hline Pizca & de & azúcar, canela, nuez moscada, pimienta, sal... \\
\hline Ráfaga & de & aire, luz, lluvia, viento... \\
\hline Rodaja & de & calabacín, cebolla, limón, naranja, patata... \\
\hline Soplo & de & aire, brisa, viento... \\
\hline Terrón & de & azúcar \\
\hline Tira & de & calabacín, carne, pimiento, zanahoria.... \\
\hline Toque & de & color, luz... \\
\hline Tramo & de & camino, carretera \\
\hline Viruta & de & chocolate, jamón, madera, queso... \\
\hline
\end{tabular}

Tabla 2. Acotadores que seleccionan sustantivos concretos.

Como se puede apreciar en los ejemplos mostrados en la tabla 2, un mismo sustantivo base puede ser seleccionado por distintos acotadores a fin de denotar diferentes formas; prueba de ello es el sustantivo queso, que, además de loncha, admite el sustantivo viruta; en este último caso, la parte acotada presenta forma alargada, curvada o espiral y no suele superar los tres centímetros de largo.

\footnotetext{
${ }^{6}$ Cabe precisar que tanto sal como azúcar poseen forma plural (las sales minerales, los azúcares en la sangre), pero no en las acepciones consideradas arriba, donde remiten a sustancias que se usan para sazonar alimentos y que funcionan como sustantivos no contables.
} 


\subsubsection{Sustantivos acotadores que seleccionan sustantivos abstractos.}

Hasta ahora hemos analizado algunos de los sustantivos acotados que remiten a referentes concretos, de manera especial, a alimentos. Sin embargo, los acotadores también seleccionan sustantivos abstractos; así tendremos un chorro de energía o una brizna de esperanza. Al igual que ocurre con los sustantivos concretos, los acotadores nos permiten hacer referencia a una parte del todo, es decir, cuantificar la intensidad o la grandeza que queremos delimitar de nuestro referente.

Al combinarse con ciertos sustantivos abstractos, los acotadores adquieren significado metafórico, generalmente asociado a las características de los referentes concretos que seleccionan, como se puede observar entre chorro de agua y chorro de energía. De hecho, con chorro de agua nos referimos a una cantidad de agua que sale de un conducto abundante y vehementemente, así como nos puede asaltar un ímpetu (un chorro) de energía. Esta relación es aún más evidente con los sustantivos viento e inspiración, puesto que los dos admiten al menos tres sustantivos acotadores que expresan el diferente grado de intensidad con el que se manifiesta el referente acotado; de ahí que podamos decir un soplo de viento y una racha / ráfaga de viento y un soplo de inspiración y una racha / ráfaga de inspiración. Como sabemos, un soplo de viento es menos intenso y más breve que una racha o ráfaga de viento, por lo que, por extensión, con un soplo de inspiración hacemos referencia a un acto breve y puntual de estímulo creador y con racha o ráfaga a una intensa sucesión de ideas que se extiende en un lapso de tiempo mayor.

Además, cabe notar que el grado de fijación colocacional entre sustantivos acotadores y sustantivos acotados abstractos es menor con respecto al que se da entre acotadores y sustantivos concretos; lo cual se refleja en una mayor libertad combinatoria entre una determinada base léxica y sus colocativos sinónimos. Como botón de muestra, el sustantivo esperanza admite al menos cuatro sustantivos acotadores, pizca, hilo, brizna y atisbo, que, asociados a esperanza, adquieren el significado de 'un poco de'. No obstante, pizca en una pizca de esperanza es más informal que los otros acotadores y, probablemente, el más usado por esta misma razón. En cambio, atisbo, con el que nos referimos a un "indicio o iniciación todavía débil de una cosa" (DUE), es el que más connotación tiene por su significado preciso y no modificable. No es ninguna casualidad que, en virtud de su significado, no funcione como los demás acotadores, que, al contrario, seleccionan también sustantivos concretos; atisbo es un ejemplo de sustantivo acotador que selecciona preferentemente sustantivos abstractos (un atisbo de duda / preocupación / remordimiento) 7 . Al igual que atisbo, hay más acotadores que seleccionan preferentemente sustantivos abstractos. En efecto, como señala Bosque (1999: 51):

[...]algunos sustantivos acotadores se especializan [...] en los abstractos, como en el caso de arrebato, que selecciona sustantivos que denotan determinadas emociones, pasiones o estados anímicos (cólera, ira, fanatismo, locura, celos, etc.) o ápice, que restringe mucho menos a sus complementos inmateriales (fuerza, confianza, esperanza, gravedad, etc.).

\footnotetext{
7 De todos modos, es posible ver atisbo combinado con sustantivos concretos, tal y como se aprecia en los siguientes ejemplos extraídos de CORPES XXI: atisbo de sudor, atisbo de vello.
} 
En la siguiente tabla mostramos algunas de las colocaciones formadas por sustantivos acotadores y sustantivos acotados abstractos:

\begin{tabular}{|l|c|l|}
\hline S. ACOTADOR & DE & S. ACOTADO(S) ABSTRACTO(S) \\
\hline Ápice & de & confianza, convicción, esperanza, sinceridad... \\
\hline Arranque & de & celos, indignación, ira, locura, lucidez, orgullo... \\
\hline Arrebato & de & amor, celos, cólera, ira, locura, odio, pasión, rabia... \\
\hline Asomo & de & duda, emoción... \\
\hline Ataque & de & celos, cólera, desesperación, ira, rabia... \\
\hline Atisbo & de & duda, esperanza, optimismo, preocupación, rencor... \\
\hline Brizna & de & esperanza, felicidad, ironía, odio, sentido común... \\
\hline Chorro & de & energía \\
\hline Chute & de & energía, felicidad... \\
\hline Dosis & de & emoción, optimismo... \\
\hline Golpe & de & suerte \\
\hline Hálito & de & emoción, esperanza... \\
\hline Hilo & de & esperanza \\
\hline Ímpetu & de & grandeza, venganza... \\
\hline Inyección & de & alegría, confianza, energía, optimismo... \\
\hline Pizca & de & esperanza, humor, ironía, remordimiento, sarcasmo... \\
\hline Racha/ráfaga & de & inspiración, suerte... \\
\hline Soplo & de & felicidad, ilusión, inspiración, optimismo... \\
\hline Toque & de & elegancia, feminidad, imaginación, sofisticación... \\
\hline
\end{tabular}

\subsubsection{Los sustantivos acotadores en las variedades diatópicas del español}

Cuando hablamos de léxico, no podemos eximirnos de pensar en las distintas variedades diatópicas del español. Como sabemos, un mismo sustantivo puede emplearse en las diferentes variedades para hacer referencia a distintos referentes; ejemplo de ello es el sustantivo cartera, usado en el español peninsular para nombrar 'un objeto plegable de pequeñas dimensiones que se usa para guardar dinero en efectivo o tarjetas' y que en muchas de las variedades latinoamericanas corresponde al bolso del español peninsular.

Un caso parecido al que acabamos de mencionar se da también entre los acotadores. A título de ejemplo, en el español peninsular el sustantivo rebanada se usa preferentemente con pan y, por consiguiente, con alimentos que contienen un alto porcentaje de harina, como bizcocho o tarta. En cambio, en muchos países latinoamericanos rebanada, además de pan, selecciona referentes de distinta naturaleza alimenticia; en el CORPES XXI encontramos así: rebanada de aguacate / carne / cebolla / naranja / pescado / piña / plátano en textos de la variedad mexicana, rebanada de huevos duros / piña / tocino en la variedad colombiana y rebanadas de carne y de tocino en el español de Perú, para citar algunos.

Además, se da otro caso de contraste entre variedades: la existencia de una unidad léxica en una determinada variedad diatópica que, al contrario, no forma parte del acervo léxico de otras. En lo que respecta a los acotadores, la Nueva gramática de la lengua española (2010: 829) señala el sustantivo feta de las 
variedades argentina y uruguaya en construcciones pseudopartitivas como una feta de jamón o una feta de queso. El sustantivo feta, que se usa para delimitar tajadas de fiambre y de queso, procede del italiano fetta (una fetta di prosciutto, es decir, una feta de jamón) y equivale al acotador loncha de las variedades peninsular, chilena y colombiana, entre otras.

De todo ello se desprende la importancia de ser constantes en el proceso de enseñanza-aprendizaje de los sustantivos cuantificativos de una determinada variedad diatópica del español y, asimismo, de ser conscientes de las diferencias léxicas que se pueden dar en las otras variedades.

\subsubsection{Sustantivos acotadores que no forman colocaciones}

En el apartado 2.1 hemos apuntado que, en virtud de las relaciones puramente referenciales que se establecen entre los sustantivos de medida (como kilo o metro) y los sustantivos cuantificados (por ejemplo, manzanas o tela), no estamos ante colocaciones.

Dicha relación referencial se da también en las construcciones pseudopartitivas formadas por aquellos sustantivos que indican recipientes, como plato, vaso o taza, y los sustantivos que expresan su contenido (por ejemplo, pasta, agua o leche). Desde un punto de vista lingüístico, estos sustantivos no forman colocaciones, a pesar de adquirir función acotadora. Como podemos fácilmente intuir, todo sustantivo que tenga como referente un alimento puede ser seleccionado por el sustantivo plato (un plato de carne / pasta / verduras). Si bien con plato estemos acotando una porción de comida que existe en proporciones mayores, hay sustantivos que presentan rasgos más afines a los acotadores sensu strictu, es decir, cuya función lingüística primaria es la de acotar una unidad más grande; estos sustantivos son vaso en un vaso de agua, taza en una taza de leche o cucharada en una cucharada de vinagre ${ }^{8}$.

Otro rasgo que diferencia estos acotadores 'de circunstancia' de los sensu strictu es que la porción acotada es delimitada por un agente externo (la cuchara, la taza, el vaso) y no representa un fragmento o una unidad del referente seleccionado, como, al contrario, se observa en loncha de jamón o grano de uva.

El hecho de que una taza de leche no sea una colocación, sino una combinación libre de unidades léxicas, se debe a que entre taza y leche no hay ninguna relación meramente lingüística, de solidaridad semántica (como entre rebanada y pan) o de preferencia estilística (como ocurre entre desear y fervientemente frente a desear mucho). Entre taza y leche no se establece ninguna relación biunívoca por la que uno de los dos sustantivos atrae en su campo léxico (y colocacional) al otro.

Con el fin de evidenciar la afinidad que muestran los sustantivos de medida con los acotadores que remiten a contenedores, Hamawand (2014: 119) se refiere a los primeros como sustantivos de medida precisa y a los últimos como sustantivos de medida aproximada.

\footnotetext{
8 Cucharada, que indica una "porción que cabe en una cuchara" (DLE), es un ejemplo de sustantivo cuantificativo que deriva del nombre del objeto que se usa para contener o para cuantificar una determinada porción. A este respecto, cabe decir que, a pesar de que una cuchara no sea un recipiente, sí puede contener sustancias líquidas, sólidas o granulosas.
} 
2.1.1.4. Un diente de ajo Vs un diente de leche: las colocaciones usustantivo + de + sustantivo» y las locuciones nominales usustantivo + de + sustantivo»

El esquema sintáctico "sustantivo + de + sustantivo» puede dar lugar tanto a colocaciones como a locuciones nominales, por lo que en este apartado ofreceremos algunas estrategias para delimitar los dos fenómenos léxicos y, en su momento, utilizar con los alumnos la terminología adecuada.

Como hemos señalado antes, en diente de ajo el sustantivo ajo constituye la base de la colocación; es, por así decirlo, el elemento más fuerte, con una mayor carga semántica y referencial, mientras que el colocativo diente (que aquí presenta significado metafórico) sirve para delimitar una porción de una unidad entera, completa en sí, el ajo; por lo que con diente de ajo nos referimos a una parte del todo. En diente de leche, en cambio, diente posee significado recto, puesto que presenta la acepción primaria de 'órgano humano o animal que sirve para la masticación o la defensa' y el sustantivo que sigue a la preposición de (en este caso, leche) tiene la función de modificar el primer sustantivo, especificando las funciones o las características del primer referente; de ahí que con dientes de leche nos refiramos a los dientes que forman parte de la primera dentición humana o animal. Se trata, por tanto, de una locución nominal que remite a un referente completo en sí mismo.

Tal vez las funciones que dentro de una locución nominal desempeña el segundo sustantivo sean más visibles en gafas de sol y en cepillo de dientes, donde los sustantivos que siguen a la preposición de especifican la naturaleza o las funciones de las gafas y el cepillo: 'gafas que sirven para resguardarse de los rayos del sol' y 'cepillo que se usa para limpiarse los dientes'.

\subsubsection{Los sustantivos cuantificativos de grupo}

Con sustantivos cuantificativos de grupo nos referimos a aquellos sustantivos que seleccionan un complemento con el fin de delimitar una cantidad que coincide con el significado de multitud / conjunto de, como enjambre y racimo en las combinaciones enjambre de abejas y racimo de uvas.

Al igual que los acotadores, los cuantificativos de grupo comprenden tanto sustantivos genéricos, que presentan escasa connotación semántica y se combinan con un número potencialmente infinito de sustantivos, como específicos, que seleccionan un número limitado de sustantivos y con los que mantienen una relación semántica muy estrecha. Ejemplos de sustantivos genéricos son serie en la acepción de "conjunto de cosas que se suceden unas a otras y que están relacionadas entre sí" (DLE) y grupo, con el significado de "conjunto de cosas o personas que están o se consideran juntas" (DUE); mientras que serie se emplea preferentemente para cuantificar referentes inanimados abstractos (una serie de condiciones / interrogantes / problemas), grupo selecciona mayoritariamente referentes humanos (un grupo de activistas / jóvenes / turistas). Si sustantivos como serie y grupo dan lugar a combinaciones libres de unidades léxicas, los sustantivos de grupo específicos (como enjambre y racimo) dan lugar a verdaderas colocaciones.

Entre los cuantificativos de grupo con significado específico encontramos los que seleccionan referentes animales, como banco en banco de peces y bandada en 
bandada de pájaros. Como señala Corpas Pastor (1996: 74), en estos casos "se dan a menudo relaciones de solidaridad léxica entre los colocados, donde el primer sustantivo (el colocativo) está determinado semánticamente por el segundo (la base)". Un ejemplo de ello es bandada, en la acepción de "grupo numeroso de aves $u$ otros animales alados que vuelan juntos" (DLE).

A continuación, recopilamos algunas de las colocaciones que se forman a partir de sustantivos cuantificativos de grupo:

\begin{tabular}{|l|c|l|}
\hline S. DE GRUPO & DE & S. CUANTIFICADO(S) \\
\hline Banco & de & peces (atunes, tiburones, truchas, etc.) \\
\hline Bandada & de & pájaros (gaviotas, golondrinas, etc.)... \\
\hline Ciclo & de & conferencias, estudios, seminarios, talleres... \\
\hline Enjambre & de & abejas, avispas \\
\hline Fajo & de & billetes, documentos, entradas, papeles... \\
\hline Jauría & de & perros \\
\hline Juego & de & Ilaves, ropa interior, sábanas, tazas, toallas... \\
\hline Manada & de & búfalos, caballos, elefantes, jabalies, lobos, toros... \\
\hline Manojo & de & espárragos, hierbas (romero, tomillo...), llaves... \\
\hline Piara & de & cerdos \\
\hline Ráfaga & de & balas, disparos, proyectiles, tiros... \\
\hline Ramillete & de & flores, hierbas (albahaca, menta, perejil...) \\
\hline Ramo & de & flores (jazmines, rosas, tulipanes, etc.) \\
\hline Racimo & de & uvas, cerezas, plátanos... \\
\hline Rebaño & de & borregos, cabras, ovejas... \\
\hline Recua & de & mulos \\
\hline Ristra & de & ajos, cebollas \\
\hline
\end{tabular}

Cabe añadir que muchos cuantificativos de grupo presentan también significado metafórico, con lo cual pueden utilizarse para seleccionar referentes de distinta naturaleza; de ahí que podamos decir una bandada de gaviotas (significado recto), pero también una bandada de turistas (significado metafórico), donde bandada adquiere una connotación negativa, al significar "grupo numeroso y, en general, ruidoso de personas" (DUE). Además, si los sustantivos de grupo que seleccionan animales, al adquirir significado metafórico, tienden a delimitar referentes humanos (un enjambre de periodistas, una manada de chavales), los que cuantifican referentes concretos inanimados (una ristra de cebollas) seleccionan preferentemente sustantivos con referentes no humanos (una ristra de preguntas).

Finalmente, como señala la Nueva gramática de la lengua española (2010: 824), algunos sustantivos pueden ser tanto acotadores como cuantificativos de grupo dependiendo de la unidad léxica con la que se combinen, como ráfaga, que, en las colocaciones ráfaga de luz / lluvia / viento funciona como acotador, puesto que acota una unidad de luz, lluvia o viento, mientras que en ráfaga de ideas / imágenes desempeña la función de cuantificativo de grupo, ya que hace alusión a un conjunto de ideas / imágenes que se presentan de forma sucesiva y repentina. 
Como se puede notar, en el primer caso los sustantivos seleccionados presentan número singular, mientras que en el segundo se encuentran en número plural.

\section{Una mirada contrastiva hacia otros idiomas}

Al principio de este artículo hemos apuntado que la falta de reciprocidad en las relaciones combinatorias a las que dan lugar los sustantivos cuantificativos del español con respecto a las que establecen los cuantificativos de otros idiomas es uno de los factores que pueden dificultar la retención y el uso adecuados de las colocaciones usustantivo + de + sustantivo" por parte de los estudiantes de E/LE; lo cual puede llevarlos a transferir al español un determinado sustantivo cuantificativo sobre la base de los patrones combinatorios de su lengua materna.

Como botón de muestra de dichas asimetrías combinatorias tomemos el sustantivo cuantificativo de grupo del inglés bunch, con el que se indica "a number of things of the same type fastened together or in a close group" (Cambridge Dictionary), es decir, un conjunto de entidades que pertenecen a una misma categoría y que están atadas o forman un grupo. El sustantivo bunch en construcciones pseudopartitivas puede combinarse con los sustantivos flowers, grapes and keys, entre otros; esto es, flores, uvas y llaves, respectivamente. En español, en cambio, cada uno de estos sustantivos es seleccionado por un cuantificativo de grupo distinto; por lo que, si en inglés se dice a bunch of $\sim$ flowers / grapes / keys, el alumno anglófono deberá saber que en español hablamos de un ramo de flores, un racimo de uvas y un manojo de llaves.

Al contrario, en alemán la estructura sintáctica "sustantivo + de + sustantivo» presenta distintas correspondencias sintácticas. Si consideramos la colocación diente de ajo, esta equivale al sustantivo femenino compuesto Knoblauchzehe, donde Knoblauch significa ajo y zehe (Zehe en su forma aislada), que aquí desempeña la función de acotador, significa dedo del pie. Lo mismo ocurre en ein Bienenschwarm (un enjambre de abejas), donde Bienen equivale a abejas y schwarm (Schwarm) a enjambre. Sin embargo, el alemán también dispone de otra estructura sintáctica con la que introducir algunas de estas colocaciones, la de «sustantivo cuantificativo + sustantivo cuantificado» separados por un espacio en blanco y actualizados en el discurso por un determinante que precede al primer sustantivo, como en eine Prise Salz (una pizca de sal) y eine Scheibe Brot (una rebanada de pan). De todos modos, muchas de estas colocaciones también presentan una forma analítica univerbal, que deriva de la inversión del orden de los dos sustantivos y de su fusión en un sustantivo compuesto, como podemos observar en Brotscheibe.

Los casos de asimetría presentados para el inglés pueden considerarse como una manifestación de lo que en el ámbito de la lingüística contrastiva Cliffard Pastor (1967 apud Brown, 1994: 196) define split (separación, divergencia), un fenómeno que ocurre cuando un ítem (una unidad léxica, una estructura sintáctica, un fonema, etc.) de la lengua materna del estudiante corresponde a dos o más ítems en la lengua meta, lo cual se materializa en la necesidad por parte del estudiante de hacer frente a una nueva distinción. Si llevamos este fenómeno al terreno colocacional, el hecho de que una unidad léxica de la lengua materna del estudiante -pongamos, el colocativo- corresponda a dos o más unidades léxicas del español podría llevarlo a utilizar una de las unidades léxicas españolas 
correspondientes al supuesto colocativo de su lengua materna para seleccionar diferentes bases.

Por otro lado, los ejemplos propuestos para el alemán pueden considerarse como una manifestación de la llamada coalescence (literalmente, fusión), que ocurre cuando dos ítems de la lengua materna corresponden a uno solo en la lengua meta, con lo cual el estudiante deberá sobrepasar una distinción a la que está acostumbrado por influencia de su lengua materna (ibid: 195). Aunque este último caso de asimetría entre las dos lenguas pueda resultar ventajoso para el estudiante alemán de $\mathrm{E} / \mathrm{LE}$, el hecho de que no se le presente explícitamente el contraste sistemático entre las estructuras de las dos lenguas podría llevarlo a transferir los patrones léxicos y sintácticos de su lengua materna a la lengua extranjera.

El hecho de transferir un lexema de una lengua a otra $y$, de ahí, de cometer errores también se debe a que los sustantivos cuantificativos, a pesar de seleccionar porciones específicas de la realidad, en muchos casos no presentan un significado delimitable. Si retomamos el sustantivo cuantificativo de grupo del inglés bunch, la definición que ofrece el diccionario Cambridge es ejemplificadora: "a number of things of the same type fastened together or in a close group". Como sabemos, "un conjunto de cosas de una misma categoría' no solo es genérico, es decir, aplicable a distintos referentes, sino que esta definición es aplicable a varios sustantivos que desempeñan la función de cuantificativos de grupo y que seleccionan otros referentes.

\section{Las colocaciones usustantivo + de + sustantivo» en el lexicón mental de una muestra de hablantes no nativos de español}

Hasta aquí nos hemos dedicado a analizar las colocaciones objeto de estudio desde una perspectiva teórica y prescriptiva. Pasemos ahora a averiguar qué lugar ocupan los sustantivos cuantificativos y las colocaciones pseudopartitivas en el lexicón mental de una muestra de 15 hablantes de E/LE cuyas competencias lingüísticas en la lengua extranjera van desde los niveles intermedios B 1-B2 hasta los avanzados C1-C2. A tal fin, hemos elaborado un test lingüístico centrado en las colocaciones usustantivo cuantificativo + de + sustantivo cuantificado concreto».

Hacemos notar que la decisión de no incluir en la investigación a estudiantes de niveles principiantes se debe al hecho de que consideramos la enseñanza de la mayoría de las colocaciones usustantivo + de + sustantivo» incompatible con estos niveles. De hecho, los sustantivos cuantificativos y las unidades léxicas que seleccionan dan lugar a combinaciones que pueden resultar complejas de descodificar y de recodificar y poco necesarias para las fases iniciales de aprendizaje, donde el alumno aún debe familiarizarse con los sustantivos que los acotadores y los cuantificativos de grupo seleccionan.

\subsection{Metodología}

En los siguientes subapartados nos dedicaremos a las preguntas que han motivado nuestra investigación, a la metodología empleada para redactar el test lingüístico, 
a los requisitos en los que nos hemos basado para seleccionar los informantes y al análisis de los resultados del test?.

\subsubsection{Preguntas de investigación}

El presente estudio nace y se desarrolla a partir de las siguientes preguntas de investigación:

- P1: ¿Qué conocimiento tienen los estudiantes/hablantes de E/LE de nivel intermedio y avanzado de las colocaciones «sustantivo + de + sustantivo»?

- P2: ¿EE conocimiento de estas colocaciones es cuantitativa y cualitativamente proporcional al nivel lingüístico general del estudiante/hablante conforme este va avanzando en su aprendizaje de E/LE? En otras palabras, ¿̇conoce más colocaciones usustantivo + de + sustantivo» el hablante de nivel avanzado que el de nivel intermedio?

\subsubsection{Informantes}

Para la realización del test contactamos con 15 informantes de diferentes edades, ocupaciones y nacionalidades. En concreto, contamos con dos informantes alemanes (uno de los cuales, además del alemán, tiene como lengua materna el ruso), dos brasileños, dos chinos, dos estadounidenses, dos franceses, un finlandés, un japonés, un suizo (de lengua materna francesa), un taiwanés (de lengua materna china) y un turco naturalizado finlandés.

En cuanto a la selección de los informantes, hemos tenido en cuenta cuatro requisitos esenciales:

a) que hayan estudiado el español peninsulario;

b) que tengan un dominio activo del español, es decir, que lo utilicen o bien cotidianamente o bien con una frecuencia regular en sus comunicaciones orales y escritas;

c) que hayan estudiado español al menos dos años en algún centro de enseñanza, tanto pública (colegio, instituto, universidad) como privada (academias de idiomas);

d) que tengan la edad mínima de 19 años (de modo que todos hayan completado su formación escolar obligatoria).

En lo que atañe a la modalidad de ejecución del test, 8 informantes completaron la sección relativa a sus datos personales y las tres pruebas que lo componen de forma presencial en la ciudad de Salamanca (España); en cambio, los 7 restantes (la mayoría de los cuales vive en su país de origen) realizó el test en el ordenador recibiendo las instrucciones sobre su contenido y su desarrollo por llamada

\footnotetext{
9 Esta investigación se ha llevado a cabo a lo largo del año académico 2017-2018 en el marco del programa de doctorado en Español: Investigación Avanzada en Lengua y Literatura de la Universidad de Salamanca (España).

10 Dicho requisito se debe a que esta es la variedad objeto de estudio. Sin embargo, esto no excluye que algunos de los informantes hayan entrado en contacto con otras variedades diatópicas del español.
} 
telefónica ${ }^{11}$. A este respecto, es importante subrayar que, a fin de que los dos grupos realizaran el test de la forma más parecida posible, los informantes del segundo grupo recibieron el test por correo electrónico solo una vez empezada la llamada telefónica; con lo cual pudimos guiarles paso a paso en su realización y asegurarnos de que lo completaran en el tiempo estimado de 15/20 minutos sin ninguna herramienta de ayuda.

\section{1.3. Instrumento de recogida de datos: el test lingüístico}

El test lingüístico nos ha parecido el mejor instrumento para obtener los datos necesarios al análisis cualitativo y cuantitativo que llevaremos a cabo a partir de las respuestas de los informantes. El hecho de confeccionar personalmente cada una de las pruebas que componen el test y de elegir arbitrariamente las unidades léxicas sobre las que queremos dirigir la atención de los informantes nos permite llegar a la obtención de los datos de interés de una forma más rápida y directa respecto a otros instrumentos de recogida de datos.

Con el objeto de ofrecer una visión más completa de todos los pasos que componen esta investigación, a continuación presentamos nuestro test.

\section{Test}

\section{Acerca de ti}

1) ¿Cuál es tu nacionalidad?

2) ¿Cuál es tu lengua materna?

3) ¿Dónde has estudiado español?

4) ¿Cuántos años has estudiado / llevas estudiando español?

5) ¿ ¿uánto tiempo llevas viviendo en España? 12

6) ¿Qué idiomas extranjeros hablas / has estudiado?

7) ¿A qué te dedicas actualmente?

8) ¿Qué nivel de español crees que tienes? 13

\section{Prueba 1.}

Escribe en las siguientes casillas las palabras que asocias a cada uno de los sustantivos propuestos. Tendrás un minuto para rellenar cada casilla.

\section{Chorro}

\footnotetext{
11 A este respecto, cabe señalar que, debido a problemas técnicos, el informante 15 recibió las instrucciones mediante una herramienta de mensajería instantánea. A pesar de ello, se le envió el test por correo electrónico solo una vez empezada la comunicación por escrito; realizó el test en tiempo real y lo remitió a nuestra dirección de correo electrónico aproximadamente 20 minutos después de haberlo recibido.

12 Esta es la única pregunta de todo el test que difiere en la versión dirigida a los informantes que han realizado el test desde casa, a los que preguntamos por si han vivido alguna vez en un país de habla hispana y, en caso de que sí, por cuánto tiempo.

13 En concreto, pedimos a los informantes que determinaran su nivel de español de acuerdo con los niveles establecidos por el Marco común europeo de referencia para las lenguas: aprendizaje, enseñanza, evaluación (MCER).
} 
Grano

Loncha

Pizca

Rodaja

Prueba 2.

Lee atentamente las siguientes preguntas ayudándote con las imágenes facilitadas ${ }^{14}$. Después, marca la opción que consideres correcta.

1. ¿Cómo se llaman las porciones en las que se dividen naturalmente las naranjas o las mandarinas?

a) Copos

b) Dientes

c) Gajos

d) Lonchas

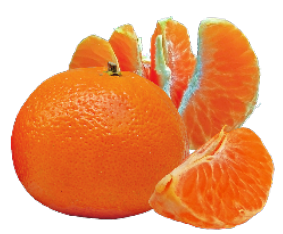

3. ¿ Cómo se llama una porción de pan cortada a lo largo de su diámetro?

a) Grano

b) Placa

C) Rebanada

d) Viruta
2. ¿Cómo se llaman las porciones en las que se divide naturalmente el ajo?

a) Dientes

b) Gajos

C) Placas

d) Rodajas

4. ¿ Cómo se llama una unidad, un filamento de hierba?

a) Brizna

b) Grano

C) Hilo

d) Viruta

\footnotetext{
14 Señalamos que las imágenes utilizadas están libres de derechos de autor y han sido descargadas del sitio web Pixabay: https://pixabay.com/es/.
} 
5. ¿Cómo se define a un grupo de abejas que están o se mueven juntas?
a) Baraja
b) Enjambre
c) Jauría
d) Racimo

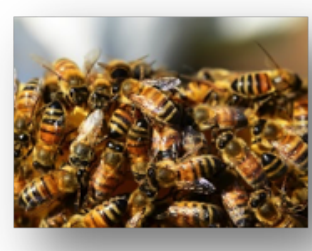

7. ¿Cómo se llama un grupo de pájaros que vuelan juntos?
a) Bandada
b) Manada
C) Piara
d) Ristra

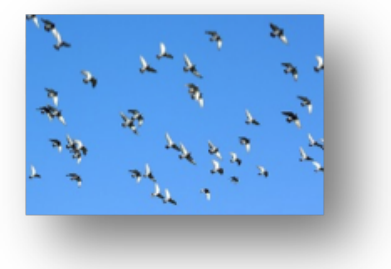

6. ¿Cómo se define a un grupo de ovejas que están al cuidado de un pastor?
a) Bandada
b) Enjambre
C) Rebaño
d) Recua

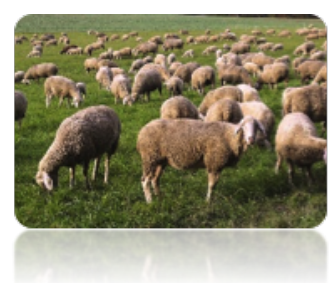

8. ¿Cómo se define a un conjunto de llaves que están atadas a un anillo?
a) Baraja
b) Manojo
C) Ramo
d) Ristra

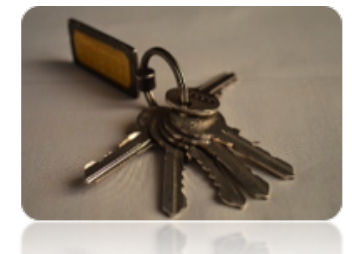

\section{Prueba 3.}

Lee atentamente la siguiente receta de cocina. A continuación, completa los espacios en blanco con las palabras que consideres más adecuadas. En algunos casos hay varias opciones posibles.

Pelar y picar las cebollas en Machacar los de ajo. Pelar las naranjas y cortarlas en de $1 \mathrm{~cm}$ de grosor. Picar el pimiento en tiras. Echar un de aceite en una sartén y esperar a que se caliente. Añadir los contramuslos de pollo y dorarlos. Escurrirlos y reservarlos. En la misma sartén, rehogar la cebolla picada con el jengibre y los ajos machacados durante 5 minutos. Retirarlos del fuego y echarlos sobre los contramuslos.

Agregar las tiras de pimiento. Precalentar el horno a $180^{\circ}$. Echar en un cuenco un de vinagre, el caldo de pollo y una de sal. Echar un poco de esta mezcla en la fuente, sobre los trozos de pollo. Hornear el pollo durante 20 minutos. Retirarlo del horno y, finalmente, añadir las de naranja a la fuente del pollo. 


\subsubsection{Descripción de la elaboración y de la ejecución del test}

Como se puede observar en el apartado anterior, la sección introductoria del test contiene ocho preguntas de carácter informativo relativas a los datos personales de los informantes que consideramos relevantes para los resultados del mismo (nacionalidad, lengua materna, lenguas estudiadas, años de estudio del español, etc.) ${ }^{15}$.

En cuanto al núcleo del test, este consta de tres pruebas de distinto formato y con diferentes finalidades, de modo que en cada una de ellas podamos investigar un determinado aspecto relativo al conocimiento que los informantes tienen de los sustantivos cuantificativos y de las colocaciones a las que dan lugar. A este respecto, cabe señalar que nuestro interés se centra en las colocaciones formadas por sustantivos cuantificativos y sustantivos cuantificados concretos, ya que estos últimos deberían ser los primeros que se presentan a los estudiantes a la hora de enseñar las colocaciones objeto de estudio $y$, por consiguiente, los que más deberían conocer en términos cuantitativos. Asimismo, gran parte del test gira alrededor de los sustantivos acotadores, puesto que estos forman colocaciones cuantitativamente superiores a las que se construyen a partir de los cuantificativos de grupo; con lo cual su frecuencia de uso en la lengua es significativamente más alta.

En la primera prueba nos proponemos averiguar qué unidades léxicas evocan los sustantivos acotadores propuestos (evocación); en la segunda qué sustantivos acotadores los informantes asocian a cada una de las imágenes presentadas (asociación); y en la tercera prueba analizar la competencia estratégica de los informantes a la hora de formar construcciones pseudopartitivas cuando no conozcan los sustantivos acotadores específicos que seleccionan determinadas unidades léxicas (competencia estratégica). A continuación, explicaremos más detalladamente cómo hemos confeccionado las pruebas y su modalidad de realización.

Para la elaboración de la primera prueba nos hemos basado en los ejercicios de asociación mental utilizados en los estudios de Disponibilidad léxica. Como sabemos, el fin de estos ejercicios es averiguar el léxico disponible en el lexicón mental del informante, es decir, las unidades léxicas que conoce y que, mediante estímulos de asociación mental, se activan en su memoria ${ }^{16}$. Al querer indagar sobre una parcela léxica específica, hemos considerado oportuno presentar como estímulos léxicos los sustantivos cuantificativos en lugar de los sustantivos base (como arroz o pan). De hecho, al presentar directamente las unidades léxicas a partir de las cuales queremos que el informante haga asociaciones, y de ahí forme colocaciones, podemos saber más rápidamente si conoce los sustantivos cuantificativos proporcionados.

Para esta prueba hemos seleccionado cinco sustantivos cuantificativos acotadores que presentan un alto grado de colocabilidad: chorro, grano, loncha,

\footnotetext{
15 En cambio, no consideramos relevantes las variables de sexo y edad; no obstante, como ya hemos señalado, sí tuvimos en cuenta el que los hablantes tuvieran la edad mínima de 19 años.

${ }^{16}$ En palabras de Bartol Hernández, el léxico disponible es el conjunto de "palabras que, organizadas, están en nuestro lexicón mental y están «disponibles» para ser utilizadas cuando las circunstancias comunicativas lo requieran; cuando un estímulo active el nodo cerebral adecuado" (2010: 91).
} 
pizca y rodaja. De hecho, con cuantas más unidades léxicas un sustantivo forme colocaciones, cuantas más posibilidades hay de que el informante las conozca, ya que su frecuencia de uso será mayor en virtud de las distintas coocurrencias a las que da lugar. Además de su mayor frecuencia de uso respecto a otros sustantivos acotadores y de su alto grado de colocabilidad, para su elección hemos tenido en cuenta la heterogeneidad de los referentes que seleccionan; como sabemos, chorro se especializa en sustantivos con referentes líquidos (agua, aceite), grano en referentes formados por distintas unidades separadas naturalmente (arroz, café), loncha en porciones cortadas artificialmente a partir de elementos enteros (jamón, queso), pizca en porciones de sustancias granulosas que se pueden coger con las yemas de los dedos y rodaja en porciones cortadas artificialmente a partir de referentes que presentan forma cilíndrica, oval o redonda (calabacín, patata).

En cuanto a la realización de la prueba, los informantes tuvieron un minuto de tiempo para rellenar cada casilla. Además de leer la instrucción previa a la prueba, también contaron con una explicación oral de cómo llevarla a cabo, esto es, escribiendo los nombres de los referentes que pueden ser seleccionados por los sustantivos acotadores propuestos ${ }^{17}$. El máximo de puntos asignable para esta prueba es de 5, por lo que el informante obtendrá un punto por cada casilla que contenga al menos una colocación correcta, independientemente de si haya reformulado más de una.

Por otra parte, la segunda prueba responde al clásico modelo de ejercicio de opción múltiple. Como sabemos, por su misma naturaleza, esta prueba no resulta ser del todo fiable, ya que, al estar presente la respuesta entre las cuatro opciones propuestas, el informante tiene un $25 \%$ de posibilidades de acertarla aún no habiendo tenido experiencia previa de la colocación que se le pide reformular. A pesar de ello, se trata de un ejercicio eficaz, puesto que muy a menudo en el aprendizaje de lenguas extranjeras no todas las unidades léxicas que encontramos, incluidas las que buscamos en el diccionario, las almacenamos correctamente en nuestro lexicón mental; por tanto, este ejercicio resulta indispensable en un test como este, ya que permite activar esas cadenas léxicas que no siempre se quedan grabadas en nuestra memoria.

Esta prueba consta de ocho preguntas, cada una de las cuales gira alrededor de un determinado sustantivo cuantificativo. En concreto, queremos saber los nombres utilizados para indicar cuatro distintas unidades acotadas a partir de referentes enteros (la naranja o la mandarina, el ajo y el pan) o generalmente considerados en su totalidad (la hierba) y cuatro diferentes grupos de referentes (las abejas, las ovejas, los pájaros y las llaves atadas a un anillo). Para que los informantes pudieran realizar correctamente la prueba, teniendo una visión completa de lo que se les estaba preguntando, consideramos oportuno acompañar cada pregunta de una imagen del referente a cuantificar.

\footnotetext{
17 A este respecto, cabe decir que antes del comienzo del test, los informantes fueron advertidos acerca de su duración (alrededor de 15 minutos), de su modalidad de ejecución y de su contenido, ofreciéndoles una rápida y sucinta explicación de la naturaleza y del comportamiento de los sustantivos cuantificativos acotadores y de grupo y proporcionándoles ejemplos que no contuvieran las colocaciones que se forman a partir de los sustantivos cuantificativos presentes en el test.
} 
Por último, en la tercera prueba, un ejercicio de rellenar huecos a partir de una receta de cocina, queremos poner a prueba la competencia estratégica del informante en crear combinaciones léxicas pseudopartitivas a partir del referente acotado y del vocabulario del que dispone en su lexicón mental ${ }^{18}$. El uso del término combinación léxica, en lugar de colocación, no es casual. De hecho, para esta prueba daremos por correctas respuestas como un poco de aceite o una cucharada de vinagre, en lugar de las colocaciones un chorro / chorrito de aceite y un chorro / chorrito de vinagre. En todo caso, consideraremos estas respuestas como un recurso estratégico con miras a suplir las lagunas léxicas relativas al colocativo acotador que selecciona preferentemente la base acotada. Por esta misma razón, en los casos en los que los informantes hayan utilizado combinaciones de medida aproximada, no les asignaremos ningún punto.

\subsection{Análisis de los resultados}

En este apartado analizaremos los resultados que los informantes han obtenido en el test en relación con sus datos personales de carácter lingüístico.

En las siguientes tablas mostraremos las preguntas (tabla 5) y las respuestas relativas a los datos personales y de formación lingüística de los informantes, así como los resultados que han obtenido en el test (tablas 6 y 7). Como se puede observar abajo, la decisión de repartir los datos de los informantes en dos tablas respeta la doble modalidad de realización del test. No obstante ello, esta repartición es puramente práctica, ya que una de las preguntas de la sección informativa difiere en las dos pruebas. A este respecto, es importante aclarar que, si bien los dos grupos de informantes han realizado el test en distintas modalidades (presencial y en línea) y en contextos geográficos distintos, para el análisis de los resultados, no confrontaremos los datos de los dos grupos (esto es, grupo 1 vs grupo 2), sino que nos dedicaremos a analizar los datos de cada informante por separado; y solo posteriormente presentaremos una visión de conjunto que nos permita interpretar los datos desde una perspectiva general, es decir, que tenga en cuenta los resultados obtenidos por cada informante con respecto a los de los demás.

En la tabla a continuación recogemos las preguntas de la sección Acerca de ti, para que nos guíen visualmente en la lectura de las respuestas de los informantes, que encontraremos siguiendo la misma repartición de los cajones en las tablas 6 y 7.

\footnotetext{
18 Como se puede observar en el primer y en el tercer espacio de esta prueba, los sustantivos que pedimos escribir no forman parte de una estructura pseudopartitiva usustantivo acotador + de + sustantivo acotado», sino que contribuyen a formar unas locuciones adverbiales de modo constituidas por la preposición en + sustantivo acotador en número plural. La razón por la que hemos insertado este tipo de construcción fraseológica en el test responde al deseo de averiguar el conocimiento de los sustantivos acotadores en sus múltiples formas de coaparición en la lengua. Además, como se puede notar en la tercera frase (y en el tercer espacio) de esta prueba (pelar las naranjas y cortarlas en rodajas__ de $1 \mathrm{~cm}$ de grosor), el sustantivo acotador en forma de locución adverbial por el que preguntamos se convierte en la última frase y en el último espacio en el colocativo de la colocación rodajas de naranja.
} 


\begin{tabular}{|c|c|c|c|}
\hline $\begin{array}{c}\text { ¿Cuál es tu } \\
\text { nacionalidad? }\end{array}$ & $\begin{array}{c}\text { ¿Cuál es tu lengua } \\
\text { materna? }\end{array}$ & $\begin{array}{l}\text { ¿̇ónde has } \\
\text { estudiado } \\
\text { español? }\end{array}$ & $\begin{array}{c}\text { ¿Cuánto tiempo } \\
\text { has estudiado o } \\
\text { llevas estudiando } \\
\text { español? }\end{array}$ \\
\hline $\begin{array}{c}\text { ¿Cuánto tiempo } \\
\text { llevas viviendo en } \\
\text { España? }\end{array}$ & $\begin{array}{c}\text { ¿Qué idiomas } \\
\text { extranjeros, } \\
\text { además del } \\
\text { español, hablas o } \\
\text { has estudiado? }\end{array}$ & $\begin{array}{c}\text { ¿A qué te dedicas } \\
\text { actualmente? }\end{array}$ & $\begin{array}{c}\text { ¿Qué nivel de } \\
\text { español crees que } \\
\text { tienes? }\end{array}$ \\
\hline $\begin{array}{c}\text { Resultado la } \\
\text { prueba }\end{array}$ & $\begin{array}{l}\text { Resultado } 2 a \\
\text { prueba }\end{array}$ & $\begin{array}{c}\text { Resultado } 3 a \\
\text { prueba }\end{array}$ & TOTAL (\%) \\
\hline
\end{tabular}

En la siguiente tabla mostramos las respuestas de los informantes a las preguntas relativas a sus datos personales y de formación lingüística en E/LE, los resultados obtenidos en cada prueba, el resultado global alcanzado en las tres pruebas, así como su representación en términos porcentuales. Puesto que los test son anónimos, diferenciaremos los informantes por números arábigos (del 1 al 15). Asimismo, el orden de presentación de los datos de cada informante se hará de forma descendente de acuerdo con el nivel que se han autodeterminado.

\begin{tabular}{|c|c|c|c|}
\hline \multicolumn{4}{|c|}{ Informante 1} \\
\hline EE.UU. & Inglés & $\begin{array}{c}\text { Instituto y universidad } \\
\text { en EE.UU; academias } \\
\text { en México y en } \\
\text { España }\end{array}$ & 20 años \\
\hline 6 años & $\begin{array}{l}\text { Francés, alemán, } \\
\text { griego koiné y hebreo }\end{array}$ & $\begin{array}{c}\text { Organizador de } \\
\text { eventos }\end{array}$ & $\mathrm{C} 1 / \mathrm{C} 2$ \\
\hline $5 / 5$ & $5 / 8$ & $5 / 7$ & $15 / 20(75 \%)$ \\
\hline \multicolumn{4}{|c|}{ Informante 2} \\
\hline Francesa & Francés & $\begin{array}{l}\text { Colegio, instituto y } \\
\text { universidad en } \\
\text { Francia }\end{array}$ & 8 años y medio \\
\hline 7 meses & Inglés & $\begin{array}{l}\text { Estudiante de máster } \\
\text { en Derecho Privado }\end{array}$ & $C 1$ \\
\hline $0 / 5$ & $1 / 8$ & $0 / 7$ & $1 / 20(5 \%)$ \\
\hline \multicolumn{4}{|c|}{ Informante 3} \\
\hline China & Chino mandarín & $\begin{array}{c}\text { Universidad en China } \\
\text { y en España }\end{array}$ & 7 años \\
\hline
\end{tabular}




\begin{tabular}{|c|c|c|c|}
\hline 4 años & - & $\begin{array}{l}\text { Estudiante de } \\
\text { doctorado }\end{array}$ & C1 \\
\hline $0 / 5$ & $3 / 8$ & $1 / 7$ & $4 / 20(20 \%)$ \\
\hline \multicolumn{4}{|l|}{ Informante 4} \\
\hline China & Chino mandarín & $\begin{array}{c}\text { Instituto en Xian } \\
\text { (China); Universidad } \\
\text { en Xian, Madrid y } \\
\text { Salamanca }\end{array}$ & 9 años \\
\hline 3 años y medio & Inglés & $\begin{array}{l}\text { Estudiante de } \\
\text { doctorado }\end{array}$ & $\mathrm{B} 2 / \mathrm{C} 1$ \\
\hline $4 / 5$ & $4 / 8$ & $4 / 7$ & $12 / 20(60 \%)$ \\
\hline \multicolumn{4}{|l|}{ Informante 5} \\
\hline Brasileña & Portugués & $\begin{array}{l}\text { Instituto en Brasil y } \\
\text { Universidad en } \\
\text { España }\end{array}$ & 4 años \\
\hline 2 años & Inglés & $\begin{array}{l}\text { Estudiante } \\
\text { universitario }\end{array}$ & $\mathrm{B} 2 / \mathrm{C} 1$ \\
\hline $5 / 5$ & $7 / 8$ & $5 / 7$ & $17 / 20(85 \%)$ \\
\hline \multicolumn{4}{|l|}{ Informante 6} \\
\hline Alemana & Alemán & $\begin{array}{l}\text { Universidad en } \\
\text { Alemania y en } \\
\text { España }\end{array}$ & 2 años \\
\hline 6 meses & Inglés y francés & $\begin{array}{c}\text { Estudiante de } \\
\text { Filología Inglesa e } \\
\text { Hispánica }\end{array}$ & B1/B2 \\
\hline $3 / 5$ & $3 / 8$ & $2 / 7$ & $8 / 20(40 \%)$ \\
\hline \multicolumn{4}{|l|}{ Informante 7} \\
\hline EE.UU. & Inglés & $\begin{array}{c}\text { Instituto y Universidad } \\
\text { en EE.UU }\end{array}$ & 5 años \\
\hline 6 semanas & Italiano & Estudiante de Biología & B1/B2 \\
\hline $2 / 5$ & $1 / 8$ & $2 / 7$ & $5 / 20(25 \%)$ \\
\hline Informante 8 & & & \\
\hline
\end{tabular}




\begin{tabular}{|c|c|c|c|}
\hline Brasileña & Portugués & $\begin{array}{c}\text { Escuela de idiomas } \\
\text { en Brasil }\end{array}$ & 2 años \\
\hline 1 mes y medio & & $\begin{array}{l}\text { Estudiante de } \\
\text { Derecho }\end{array}$ & B1 \\
\hline $2 / 5$ & $4 / 8$ & $2 / 7$ & $8 / 20(40 \%)$ \\
\hline
\end{tabular}

A continuación, mostramos los datos y los resultados de los informantes del grupo 2. Recordamos que, si bien el contenido del núcleo del test es idéntico al que hemos dirigido al primer grupo, en la sección Acerca de ti hemos sustituido la pregunta $\dot{\imath}$ Cuántos años llevas viviendo en España con $\dot{z}$ Has vivido alguna vez en un país hispanohablante? En caso de que sí, ¿̇ónde?

\begin{tabular}{|c|c|c|c|}
\hline \multicolumn{4}{|l|}{ Informante 9} \\
\hline Japonesa & Japonés & $\begin{array}{l}\text { Universidad en } \\
\text { Japón y en España }\end{array}$ & 10 años \\
\hline $\begin{array}{c}\text { Desde hace } 8 \text { años } \\
\text { en España ( } 6 \text { en } \\
\text { Barcelona y } 2 \text { en } \\
\text { Canarias) }\end{array}$ & Inglés y catalán & $\begin{array}{l}\text { Doctorando en } \\
\text { Letras }\end{array}$ & $\mathrm{C} 2$ \\
\hline $4 / 5$ & $3 / 8$ & $4 / 7$ & $11 / 20(55 \%)$ \\
\hline \multicolumn{4}{|l|}{ Informante 10} \\
\hline Suiza & Francés & Instituto en Suiza & 4 años \\
\hline $\begin{array}{c}6 \text { meses en } \\
\text { Salamanca } \\
\text { (España) y } 1 \text { año } \\
\text { en Montevideo } \\
\text { (Uruguay) }\end{array}$ & Alemán e inglés & Asistente social & $\mathrm{C} 1$ \\
\hline $5 / 5$ & $6 / 8$ & $7 / 7$ & $18 / 20(90 \%)$ \\
\hline \multicolumn{4}{|l|}{ Informante 11} \\
\hline Francesa & Francés & $\begin{array}{l}\text { Colegio, instituto y } \\
\text { universidad en } \\
\text { Francia }\end{array}$ & 7 años \\
\hline $\begin{array}{c}1 \text { año en } \\
\text { Salamanca } \\
\text { (España) }\end{array}$ & Inglés y catalán & $\begin{array}{l}\text { Estudiante de } \\
\text { Filología Hispánica }\end{array}$ & $\mathrm{Cl}$ \\
\hline $4 / 5$ & $5 / 8$ & $4 / 7$ & $13 / 20(65 \%)$ \\
\hline
\end{tabular}




\begin{tabular}{|c|c|c|c|}
\hline \multicolumn{4}{|l|}{ Informante 12} \\
\hline Turca y finlandesa & Turco & $\begin{array}{c}\text { Universidad y } \\
\text { academia de } \\
\text { idiomas en Helsinki } \\
\text { (Finlandia) }\end{array}$ & 5 años y medio \\
\hline No & $\begin{array}{c}\text { Finés, inglés, alemán } \\
\text { y ruso }\end{array}$ & $\begin{array}{l}\text { Programador de } \\
\text { software }\end{array}$ & $\mathrm{B} 2 / \mathrm{C} 1$ \\
\hline $0 / 5$ & $1 / 8$ & $1 / 7$ & $2 / 20(10 \%)$ \\
\hline \multicolumn{4}{|l|}{ Informante 13} \\
\hline Taiwanesa & Chino mandarín & $\begin{array}{c}\text { Instituto y } \\
\text { universidad en } \\
\text { Taiwán }\end{array}$ & 4 años \\
\hline $\begin{array}{l}10 \text { meses en } \\
\text { Salamanca } \\
\text { (España) }\end{array}$ & Inglés & $\begin{array}{l}\text { Estudiante de } \\
\text { Filología Hispánica }\end{array}$ & B2 \\
\hline $2 / 5$ & $4 / 8$ & $2 / 7$ & $8 / 20(40 \%)$ \\
\hline \multicolumn{4}{|l|}{ Informante 14} \\
\hline Alemana & Alemán y ruso & $\begin{array}{l}\text { Instituto y } \\
\text { universidad en } \\
\text { Alemania }\end{array}$ & 6 años y medio \\
\hline $\begin{array}{l}5 \text { meses en } \\
\text { Salamanca } \\
\text { (España) }\end{array}$ & $\begin{array}{c}\text { Inglés, francés y } \\
\text { norvego }\end{array}$ & Asistente de ventas & B2 \\
\hline $1 / 5$ & $3 / 8$ & $2 / 8$ & $6 / 20(30 \%)$ \\
\hline \multicolumn{4}{|l|}{ Informante 15} \\
\hline Finlandesa & Finlandés & $\begin{array}{l}\text { Universidad de } \\
\text { Jyväskylä } \\
\text { (Finlandia) }\end{array}$ & 2 años \\
\hline No & $\begin{array}{l}\text { Inglés, sueco, } \\
\text { alemán, ruso, } \\
\text { francés, italiano, } \\
\text { portugués y estonio }\end{array}$ & Buscando trabajo & B1 \\
\hline $0 / 5$ & $2 / 8$ & $2 / 7$ & $4 / 20(20 \%)$ \\
\hline
\end{tabular}


Con el fin de tener una visión más clara de los resultados globales de los test de cada informante, así como de los niveles en los que se han encuadrado y de su lengua materna, presentamos la siguiente tabla. El orden de presentación de los datos es descendente de acuerdo con los resultados totales obtenidos y convertidos en porcentajes.

\begin{tabular}{|l|l|l|l|}
\hline N. informante & Total obtenido & Nivel & Lengua materna \\
\hline Informante 10 & $90 \%$ & $\mathrm{C} 1$ & Francés \\
\hline Informante 5 & $85 \%$ & $\mathrm{~B} 2 / \mathrm{Cl}$ & Portugués \\
\hline Informante 1 & $75 \%$ & $\mathrm{C} 1 / \mathrm{C} 2$ & Inglés \\
\hline Informante 11 & $65 \%$ & $\mathrm{C} 1$ & Francés \\
\hline Informante 4 & $60 \%$ & $\mathrm{~B} 2 / \mathrm{Cl}$ & Chino \\
\hline Informante 9 & $55 \%$ & $\mathrm{C} 2$ & Japonés \\
\hline Informante 13 & $40 \%$ & $\mathrm{~B} 2$ & Chino \\
\hline Informante 6 & $40 \%$ & $\mathrm{~B} 1 / \mathrm{B} 2$ & Alemán \\
\hline Informante 8 & $40 \%$ & $\mathrm{~B} 1$ & Portugués \\
\hline Informante 14 & $30 \%$ & $\mathrm{~B} 2$ & Alemán y ruso \\
\hline Informante 7 & $25 \%$ & $\mathrm{~B} 1 / \mathrm{B} 2$ & Inglés \\
\hline Informante 3 & $20 \%$ & $\mathrm{C} 1$ & Chino \\
\hline Informante 15 & $20 \%$ & $\mathrm{~B} 1$ & Finlandés \\
\hline Informante 12 & $10 \%$ & $\mathrm{~B} 2 / \mathrm{C} 1$ & Turco \\
\hline Informante 2 & $5 \%$ & $\mathrm{C} 1$ & Francés \\
\hline
\end{tabular}

El primer aspecto que destaca de los datos recogidos atañe a la falta de correlación directa entre el nivel general de español que los informantes se han autodeterminado y los resultados globales que han obtenido en el test. En otras palabras, el conocimiento de las colocaciones «sustantivo + de + sustantivo» no siempre es directamente proporcional a su nivel general de español. Como botón de muestra de una correlación directa entre las variables nivel general de español y resultado global, tomemos los informantes 1, 4 y 6. El informante 6, de nivel B1/B2, ha completado correctamente el $40 \%$ de los ítems, el número 4, de nivel B2/Cl, el 60\% y el número 1, de nivel $\mathrm{Cl} / \mathrm{C} 2$, el 75\%. A la vista de estos datos, cuanto más alto es el nivel de competencia lingüística, mayor es el número de respuestas correctas, y, por tanto, de colocaciones usustantivo + de + sustantivo» conocidas. 


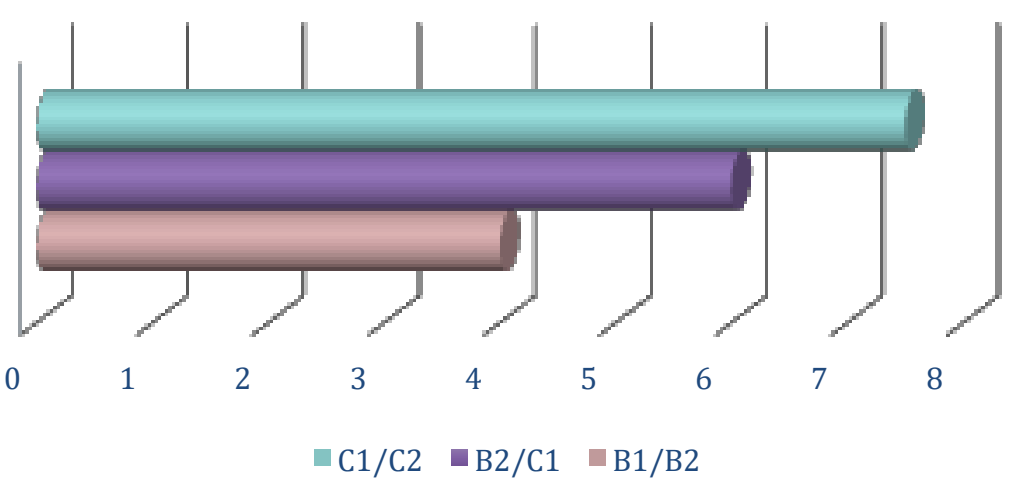

Gráfico 1

Sin embargo, no se observa la misma situación para todos los informantes; por lo que encontramos casos de hablantes de niveles avanzados que conocen menos colocaciones «sustantivo + de + sustantivo» que hablantes de niveles intermedios. A título de ejemplo, el informante 2, de lengua materna francesa, a pesar de considerarse de nivel $\mathrm{Cl}$, ha completado correctamente un solo ítem de 20 , reformulando la colocación brizna de hierba en la prueba 2, obteniendo así una puntuación del 5\%. Este resultado, de por sí bajo, resulta aún más significativo si lo comparamos con los resultados que han obtenido informantes de niveles intermedios, como el número 16, de nivel Bl y de lengua materna finlandesa, que ha completado correctamente el $20 \%$ de los ítems o el número 13 , de nivel B2 y de lengua materna china, que ha completado correctamente 8 ítems de 20, obteniendo una puntuación del $40 \%$.

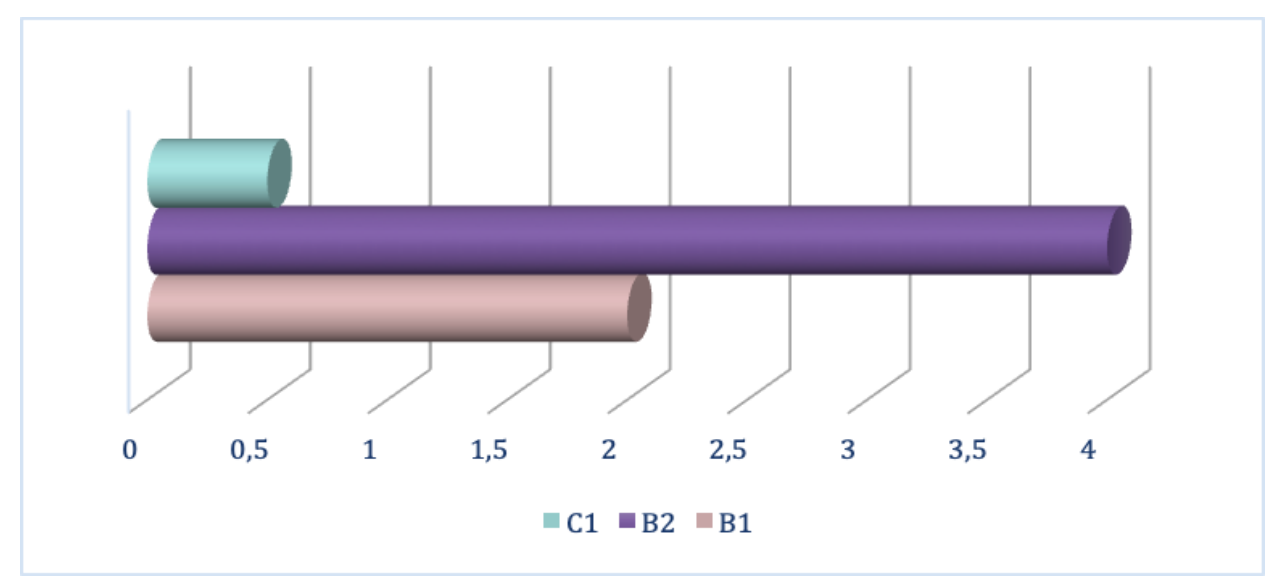

Gráfico 2

Como se puede apreciar en la tabla 8 , son varios los informantes que, a pesar de considerarse de nivel avanzado o intermedio/avanzado, han obtenido resultados significativamente más bajos que informantes que se consideran de niveles intermedios. 
Asimismo, hasta en los casos de variables afines, como ocurre entre los informantes 3 y 4 , los resultados obtenidos en el test contrastan notablemente. De hecho, a pesar de que los dos informantes sean de nacionalidad china, hayan estudiado español tanto en la universidad en China como en España, lleven aproximadamente el mismo tiempo viviendo en España y sigan el mismo curso de doctorado, el informante que se ha encuadrado en el nivel $\mathrm{Cl}$ ha completado correctamente 4 ítems de 20, es decir, el 20\% del test, mientras que el número 4, que se considera de nivel $\mathrm{B} 2 / \mathrm{Cl}$, ha rellenado correctamente 12 ítems de 20, alcanzando una puntuación del 60\%. Además, cabe notar que en la prueba significativamente más fiable, la número 1, el informante 3 ha rellenado 2 casillas de 5, pero aportando datos que no consideramos correctos. Al contrario, el informante 4 ha rellenado 4 casillas de 5 , formando más de doce colocaciones y demostrando así su notable conocimiento de los sustantivos cuantificativos propuestos.

En las siguientes tablas mostramos las combinaciones léxicas que los informantes 3 y 4 han formado en la prueba número 1.

\begin{tabular}{|l|l|}
\hline \multicolumn{2}{|l|}{ Informante 3(C1) } \\
\hline Grano & fenómeno del tiempo, pieza \\
\hline Loncha & pez, pescadería \\
\hline
\end{tabular}

Tabla 9

\begin{tabular}{|l|l|}
\hline \multicolumn{2}{|l|}{ Informante $\mathbf{4}$ (B2/C1) } \\
\hline Grano & arroz, trigo, guisante, sal gruesa \\
\hline Loncha & queso, jamón, salchicha \\
\hline Pizca & sal, azúcar, pimienta, romero, polvo de trigo \\
\hline Rodaja & huevos \\
\hline
\end{tabular}

\subsubsection{Análisis de los resultados de la primera prueba}

Mediante esta prueba queremos comprobar cuáles de los cinco sustantivos acotadores propuestos son los más conocidos entre los informantes y averiguar cuántas y cuáles colocaciones el informante es capaz de formar, sobre la base de conocimientos previos, a partir de ellos. Por tanto, en las siguientes líneas analizaremos los resultados obtenidos tanto en términos cuantitativos como cualitativos.

Para poder entender cómo evaluamos las unidades léxicas introducidas por los informantes, señalamos en rojo las unidades léxicas que consideramos incorrectas y en azul las que, a pesar de no formar auténticas colocaciones ni dar lugar a colocaciones no prototípicas, aceptamos como respuestas posibles. En negro, en cambio, encontramos las unidades léxicas que forman colocaciones prototípicas. 


\begin{tabular}{|c|c|c|c|c|c|c|c|c|}
\hline & $\begin{array}{c}1 \\
(\mathrm{C} 1 / \mathrm{C} 2)\end{array}$ & $\begin{array}{c}2 \\
\text { (C1) }\end{array}$ & $\begin{array}{c}3 \\
(\mathrm{C} 1)\end{array}$ & $\begin{array}{c}4 \\
\text { (B2/C1) }\end{array}$ & $\begin{array}{c}5 \\
(B 2 / C 1)\end{array}$ & $\begin{array}{c}6 \\
\text { (B1/B2) }\end{array}$ & $\begin{array}{c}7 \\
\text { (B1/B2) }\end{array}$ & $\begin{array}{c}8 \\
\text { (B1) }\end{array}$ \\
\hline Chorro & $\begin{array}{l}\text { agua, } \\
\text { aceite, } \\
\text { líquido, } \\
\text { manantial, } \\
\text { fuente }\end{array}$ & & & & $\begin{array}{l}\text { agua, } \\
\text { leche }\end{array}$ & & & \\
\hline Grano & $\begin{array}{c}\text { arroz, } \\
\text { cebada, } \\
\text { trigo, } \\
\text { avena }\end{array}$ & tornesol & $\begin{array}{c}\text { fenómeno } \\
\text { del tiempo, } \\
\text { pieza }\end{array}$ & $\begin{array}{c}\text { arroz, } \\
\text { trigo, } \\
\text { guisante, } \\
\text { sal gruesa }\end{array}$ & $\begin{array}{l}\text { arena, } \\
\text { café, } \\
\text { semillas, } \\
\text { sal }\end{array}$ & $\begin{array}{c}\text { arroz, } \\
\text { cuscús, } \\
\text { arena, } \\
\text { azúcar, } \\
\text { sal }\end{array}$ & $\begin{array}{c}\text { arena, } \\
\text { sal, } \\
\text { harina, } \\
\text { especias } \\
\text { varias, } \\
\text { azúcar }\end{array}$ & $\begin{array}{c}\text { arroz, } \\
\text { frijoles }\end{array}$ \\
\hline Loncha & $\begin{array}{c}\text { fiambre, } \\
\text { queso, } \\
\text { jamón }\end{array}$ & & & $\begin{array}{l}\text { queso, } \\
\text { jamón, } \\
\text { salchicha }\end{array}$ & $\begin{array}{l}\text { jamón, } \\
\text { chorizo }\end{array}$ & $\begin{array}{l}\text { pan, } \\
\text { carne, } \\
\text { cerdo, } \\
\text { salmón }\end{array}$ & & \\
\hline Pizca & $\begin{array}{c}\text { sal, } \\
\text { especias }\end{array}$ & & & $\begin{array}{c}\text { sal, } \\
\text { azúcar, } \\
\text { pimienta, } \\
\text { romero, } \\
\text { polvo de } \\
\text { trigo }\end{array}$ & sal & & & $\begin{array}{l}\text { sal, } \\
\text { salsa }\end{array}$ \\
\hline Rodaja & $\begin{array}{c}\text { cebolla, } \\
\text { pimiento, } \\
\text { pizza }\end{array}$ & & & huevos & $\begin{array}{l}\text { cebolla, } \\
\text { tomate, } \\
\text { pepinillo, } \\
\text { remolacha }\end{array}$ & $\begin{array}{c}\text { berenjena } \\
\text { torta, } \\
\text { pan, } \\
\text { calabacín }\end{array}$ & $\begin{array}{l}\text { pan, } \\
\text { postre, } \\
\text { torta, } \\
\text { pastel }\end{array}$ & \\
\hline
\end{tabular}

Tabla 11

\begin{tabular}{|l|c|c|c|c|c|c|c|}
\cline { 2 - 7 } \multicolumn{1}{c|}{} & $\begin{array}{c}\mathbf{9} \\
\text { (C2) }\end{array}$ & $\begin{array}{c}10 \\
\text { (C1) }\end{array}$ & $\begin{array}{c}11 \\
\text { (C1) }\end{array}$ & $\begin{array}{c}12 \\
\text { (B2/C1 }\end{array}$ & $\begin{array}{c}13 \\
\text { (B2) }\end{array}$ & $\begin{array}{c}14 \\
\text { (B2) }\end{array}$ & $\begin{array}{c}15 \\
\text { (B1) }\end{array}$ \\
\hline Chorro & $\begin{array}{c}\text { agua, } \\
\text { vino }\end{array}$ & agua & $\begin{array}{c}\text { agua, } \\
\text { leche }\end{array}$ & & & & \\
\hline Grano & arena & café & $\begin{array}{c}\text { limón, naranja, } \\
\text { mandarina, } \\
\text { pepino }\end{array}$ & $\begin{array}{c}\text { pan, } \\
\text { agricultura, } \\
\text { comida }\end{array}$ \\
\hline Loncha & $\begin{array}{c}\text { jamón, } \\
\text { queso }\end{array}$ & carne & $\begin{array}{c}\text { queso, } \\
\text { embutido }\end{array}$ & & $\begin{array}{c}\text { comida, } \\
\text { salchicha, } \\
\text { salchichón, }\end{array}$ & & \\
\hline
\end{tabular}




\begin{tabular}{|l|l|l|l|l|l|l|l|}
\hline Pizca & & sal & sal & & unidad & & $\begin{array}{c}\text { sal, } \\
\text { pimiento }\end{array}$ \\
\hline Rodaja & melón & limón & pan & & $\begin{array}{c}\text { receta, } \\
\text { zanahoria, } \\
\text { carne }\end{array}$ & & \\
\hline
\end{tabular}

Tabla 12

En lo que respecta a las unidades léxicas que señalamos en rojo, los errores se deben a dos motivos principales: por una parte, algunas de ellas no forman colocaciones con los sustantivos acotadores propuestos, como observamos en * grano de fenómeno del tiempo, *grano de limón o *rodaja de receta; por otra parte, algunos informantes han cometido errores de naturaleza morfológica (además de semántica), como apreciamos en *grano de tornesol o en *pizca de pimiento. En *grano de tornesol el error, que podemos clasificar de barbarismo, se debe claramente a que tornesol no es un vocablo del español; de hecho, el informante, de lengua materna francesa, ha realizado un calco gráfico del primer lexema (con función verbal) del sustantivo compuesto tournesoleil, esto es, girasol. De todas formas, el error habría persistido incluso en el caso de que el informante hubiera insertado el sustantivo girasol, puesto que este no forma ninguna colocación con el acotador grano (*un grano de girasol). En *pizca de pimiento, en cambio, el error se debe a una confusión muy recurrente entre los hablantes de E/LE, esto es, el uso del sustantivo pimiento en lugar de pimienta, y viceversa. Como sabemos, con pimiento hacemos referencia a una verdura de la familia de las solanáceas, de color rojo, verde o amarillo, mientras que el sustantivo femenino pimienta indica el "fruto del pimentero, redondo, de pequeño tamaño, picante y muy aromático, que se utiliza, molido o entero, como condimento" (DLE). Una vez molida, la pimienta adquiere una consistencia granulosa y se puede, al igual que se hace con la sal o con otras especias, coger con las yemas de los dedos; esta porción equivale a una pizca de pimienta.

Entre las unidades léxicas señaladas en azul, en cambio, encontramos las unidades léxicas que no consideramos del todo erradas $-y$ que, por tanto, puntuamos como respuestas acertadas-, pero que, o bien no forman colocaciones prototípicas (rodaja de pan), o bien no forman colocaciones sintácticas (chorro de líquido). En lo que atañe al primer caso, consideramos como colocación prototípica la combinación rebanada de pan, pero no rodaja de pan, puesto que el acotador rebanada se combina más frecuentemente con el sustantivo pan hasta crear una auténtica restricción léxica; por lo que con solo nombrar el sustantivo rebanada, evocamos a la mente el referente pan. Además, el sustantivo rebanada, así como loncha, remite a una tajada ancha y delgada de pan que puede tener diferentes formas, mientras que, si utilizamos propiamente el acotador rodaja, tanto con pan como con otros referentes, la porción cortada debería tener un tamaño inferior respecto al de la rebanada y una forma circular.

En lo que concierne a la formación de una combinación que no podemos considerar de colocación, pero que, al mismo tiempo, no es de evaluar como error, 
tomemos chorro de líquido de la casilla correspondiente a chorro / informante 1. Como sabemos, chorro de líquido no forma una verdadera colocación sintáctica, pero, al ser líquido el hiperónimo de muchos de los sustantivos que chorro selecciona (por ejemplo, agua), damos la respuesta por correcta, puesto que el informante nos está demostrando que conoce el sustantivo acotador.

Pasando a las combinaciones léxicas acertadas, a continuación presentamos las colocaciones más veces formadas por nuestros informantes a partir de los acotadores facilitados. Puesto que en algunos casos los informantes han dejado las casillas en blanco, consideramos recurrentes aquellas colocaciones que han sido reformuladas por un mínimo de cuatro veces.

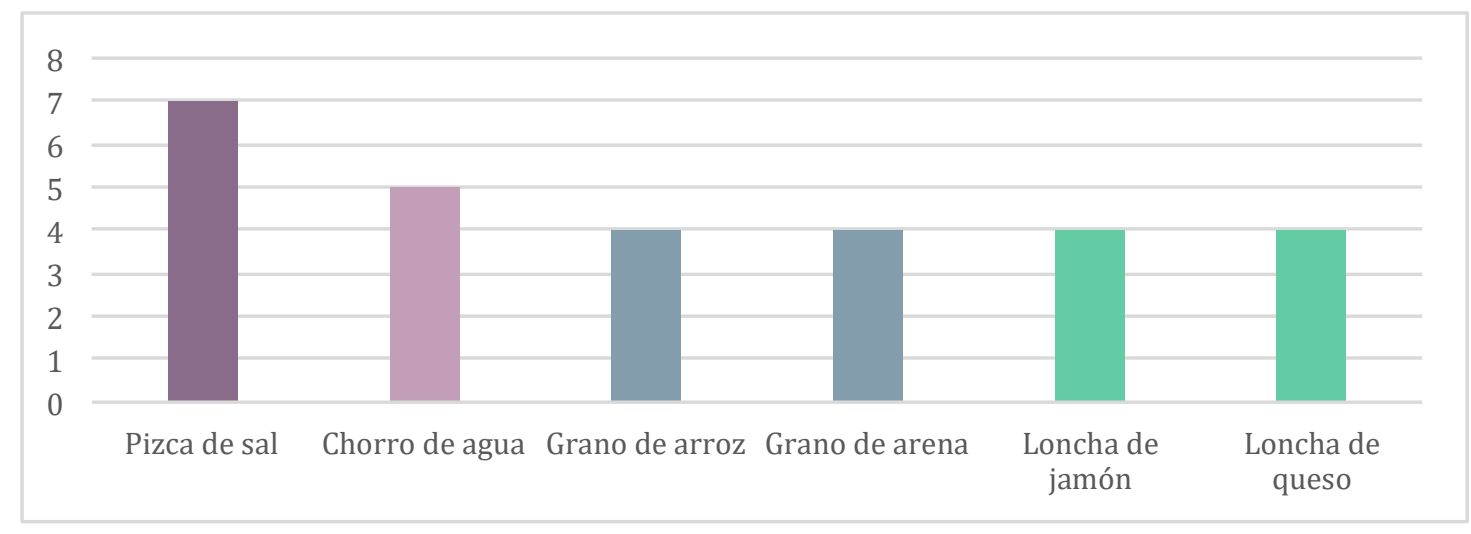

Gráfico 3

Como podemos apreciar en las tablas 11 y 12, las colocaciones mayormente reformuladas son pizca de sal, chorro de agua, grano de arroz, grano de arena, loncha de jamón y loncha de queso. Curiosamente, la colocación reconstruida por el mayor número de informantes -en concreto, 7- es pizca de sal, a la que le sigue chorro de agua, formulada por 5 informantes; las otras 4, en cambio, han sido reconstruidas 4 veces cada una. A este respecto, cabe decir que el hecho de que una colocación como pizca de sal haya sido reconstruida por el mayor número de informantes no significa que el sustantivo acotador pizca sea más frecuente en la lengua o más activo en el lexicón mental de los informantes que otros sustantivos acotadores. Para corroborar esta afirmación, basta con echar un vistazo al número de coocurrencias que han sido reelaboradas a partir de los sustantivos grano y loncha. Como podemos observar en las tablas 11 y 12, el sustantivo grano ha sido colocado junto con sustantivos que remiten a cereales, como arroz, avena, cebada, trigo, a sustancias granulosas usadas para sazonar la comida (sal y azúcar), así como a otros referentes formados por unidades en forma granular (arena), redonda u oval (grano de café). Por su parte, el sustantivo loncha, uno de los acotadores más productivos del español peninsular, ha sido colocado junto con referentes que permiten ser cortados a lo largo de su diámetro (jamón, queso, carne, pan, etc.). Al contrario, el sustantivo pizca, al seleccionar referentes que presentan consistencia granulosa, como la sal o las especias, se combina con un número significativamente inferior de sustantivos. De ello se desprende cómo los sustantivos que forman auténticas restricciones léxicas se quedan grabados en la memoria como bloques léxicos y, por tanto, permiten ser activados en el lexicón 
mental de una forma más rápida que sustantivos que forman múltiples colocaciones.

\subsubsection{Análisis de los resultados de la segunda prueba}

La segunda prueba responde al clásico modelo de ejercicio de respuestas múltiples, con lo cual contamos con un margen de respuestas acertadas que pueden no depender de conocimientos previos. A título de ejemplo, la colocación brizna de hierba equivale en francés a brin d'herbe y rebaño de ovejas corresponde a rebanho de ovelhas en portugués; de ahí que los informantes que tienen el francés o el portugués como lengua materna pueden haber reformulado correctamente dichas colocaciones simplemente en la base de paralelismos léxicos. No obstante, los datos que hemos obtenido de esta prueba resultan muy interesantes.

En el siguiente gráfico mostramos las colocaciones reformuladas con éxito.

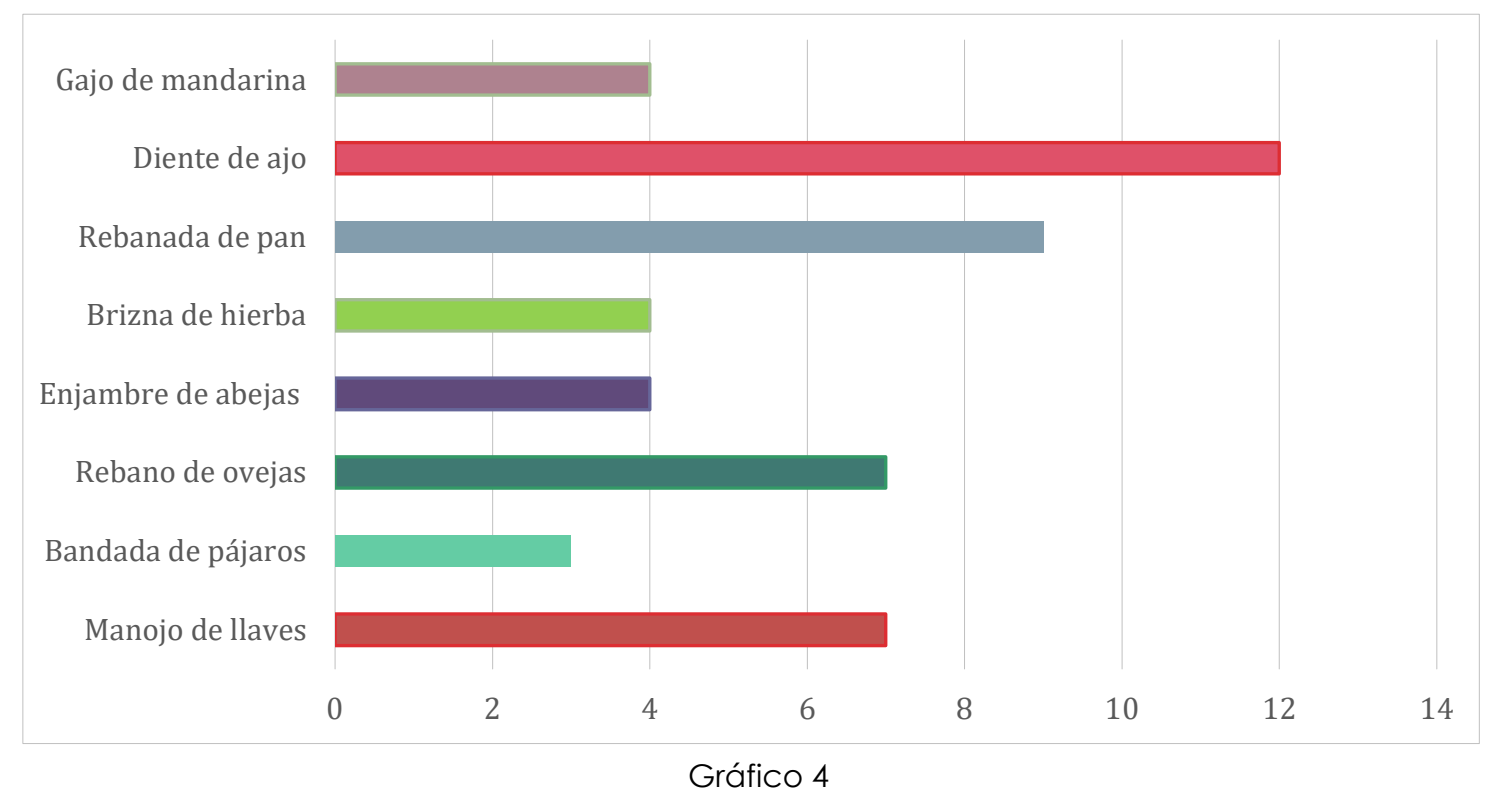

A primera vista, el dato que más destaca atañe a la colocación más veces reconstruida, diente de ajo, reformulada por 12 informantes de 15, situándose así tres puntos por encima de rebanada de pan. En el ecuador del gráfico, en cambio, encontramos las colocaciones rebaño de ovejas y manojo de llaves, reformuladas correctamente 7 veces cada una; y a la cola de la lista hallamos brizna de hierba y enjambre de abejas, combinadas correctamente por 4 informantes cada una, gajo de mandarina / naranja y bandada de pájaros, acertadas solamente por 3 informantes cada una.

Puesto que la muestra de informantes que ha realizado el test es muy heterogénea, incluyendo hablantes de E/LE de niveles intermedios, no sorprende que colocaciones como gajo de mandarina / naranja y brizna de hierba hayan sido reformuladas correctamente por 3 y 4 informantes respectivamente; pues, tanto gajo como brizna son unidades léxicas con un contenido semántico muy preciso y una frecuencia de uso relativamente baja, por lo que su aprendizaje se reserva a los niveles avanzados C1 y C2. Al contrario, resulta llamativo el hecho de que la 
mayoría de los informantes desconozca la colocación bandada de pájaros, a pesar de que el sustantivo pájaro esté entre los primeros nombres de animales que se estudian y el sustantivo bandada sea el único sustantivo cuantificativo de grupo de significado específico que lo seleccione.

Por otro lado, destaca el resultado positivo relativo a la colocación diente de ajo, reconstruida con éxito por 12 informantes de 15, superando así el número de veces en las que se ha reformulado correctamente una colocación tan frecuente como rebanada de pan; con lo cual suponemos que el éxito en la reformulación de diente de ajo se deba en parte a factores independientes de su conocimiento previo. El primer factor que encontramos es de naturaleza intralingüística $y$, en concreto, metafórica, puesto que las porciones en las que se divide naturalmente el ajo -los dientes de ajo- recuerdan a los dientes humanos o animales; de ahí que algunos informantes puedan haber hecho esta asociación en la base de dicho parecido formal. El segundo factor, en cambio, es de naturaleza interlingüística y depara muchas curiosidades idiomáticas. De hecho, en varias lenguas diente de ajo encuentra sus equivalentes en colocaciones que se combinan con el mismo sustantivo acotador, esto es, con la unidad léxica que equivale a la traducción directa de diente. Si no extraña que en portugués encontremos la colocación dente de alho, al contrario, resulta curioso ver que incluso en lenguas tipológicamente diferentes, como el ruso y el turco, el acotador diente remita al mismo referente. A título de ejemplo, en ruso -lengua indoeuropea perteneciente a la rama de las lenguas eslavas orientales- el acotador diente encuentra su equivalente directo en el sustantivo en forma diminutiva зубчик (esto es, dientecillo) у en turco -lengua de la familia túrquica con la que el español no guarda relaciones filogenéticas-, en el sustantivo diş (diente), que da lugar a la colocación sarımsak dişi (diente de ajo) ${ }^{19}$.

\subsubsection{Análisis de los resultados de la tercera prueba}

Esta prueba tiene dos objetivos; por un lado, comprobar el uso contextualizado de los sustantivos cuantificativos y, por otro, averiguar las estrategias 'de subrogación' que han empleado los informantes para formar construcciones pseudopartitivas allí donde no conocían los sustantivos cuantitificativos específicos.

Los sustantivos acotados que los informantes han combinado mayormente con sustantivos genéricos o de medida aproximada son aceite, vinagre y sal. Ejemplos de combinaciones que consideramos correctas son un poco de aceite (en echar un de aceite en la sartén y esperar a que caliente) de los informantes 4 y 7, un poco de vinagre y una cucharadita de vinagre de los informantes 4 y 7 , un poquito de sal y un poco de sal de los informantes 7 y 9 (en echar en un cuenco un de vinagre, el caldo de pollo y una de sal). Estas construcciones pseudopartitivas se convierten en recursos estratégicos eficaces, puesto que suplen el desconocimiento de las colocaciones chorro / chorrito de aceite, chorro /

\footnotetext{
19 El proceso metafórico que ha llevado al uso de un sustantivo concreto para hacer referencia a las porciones que componen una cabeza de ajo se da también en otras lenguas, pero a partir de otros referentes. Por ejemplo, en alemán la colocación diente de ajo corresponde al sustantivo compuesto Knoblauchzehe y en finlandés al sustantivo compuesto valkosipulinkynsi; mientras que el lexema con función acotadora del alemán Zehe significa literalmente dedo del pie, el sustantivo finlandés kynsi significa uña.
} 
chorrito de vinagre y pizca de sal sin crear alteraciones desde el punto de vista pragmático.

Al contrario, desde el punto de vista extralingüístico -esto es, en la preparación del plato sugerido en la receta-, no podemos considerar correctas combinaciones léxicas como una gota de aceite, un vaso de vinagre y una cuchara de sal, formadas por los informantes 6, 8 y 3, respectivamente. Como bien sabemos, si en el entorno doméstico un poquito de vinagre puede equivaler a un chorrito de vinagre, la cantidad de líquido que puede contener un vaso es significativamente superior a la que indica el acotador chorro, o su diminutivo chorrito; con lo cual un chorro o chorrito de vinagre no equivale a un vaso de vinagre. Asimismo, echar una sola gota de aceite en una sartén no será suficiente para hacer sofreír los contramuslos de pollo20; y, aún más importante, si a un plato le echamos -por equivocación, se espera- una cuchara de sal, en lugar de una pizca de sal, sería aconsejable evitar comerlo.

Pasemos ahora al análisis de los errores que atañen a la formación de construcciones pseudopartitivas que no pertenecen al español. Entre los tipos de errores que los informantes han cometido destacan tres en concreto: la creación de barbarismos, la transferencia semántica y la que definimos la no-separación conceptual, sobre los que daremos más información a continuación.

En lo que concierne a los barbarismos, considerados en la acepción de unidades léxicas inexistentes en la lengua meta y creadas a partir de interferencias con la lengua de origen del informante $o$ de una lengua tercera, analicemos las combinaciones *fio de aceite y *pincha de sal. Como bien sabemos, ni *fio ni * pincha son sustantivos acotadores del español, razón por la cual las combinaciones formadas son incorrectas. En concreto, la combinación *fio de aceite ha sido formulada por el informante 8, cuyo dominio del español corresponde al nivel B1 del MCER y, aún más importante, cuya lengua materna es el portugués. Esta última información resulta relevante, puesto que la colocación equivalente a chorro de aceite en portugués es fio de azeite; de ahí que, por falta de conocimiento de la colocación del español, el informante haya trasladado una unidad léxica de su lengua materna a la lengua meta sin aportar ninguna modificación. La otra combinación que insertamos en la categoría de los barbarismos es *pincha de sal, formulada por los informantes 2 y 6, de nacionalidad francesa y alemana, respectivamente. Si bien el sustantivo pincha se ajusta a la morfología y a la ortografía del español, la combinación *pincha de sal es claramente una transferencia de la colocación del inglés a pinch of salt (una pizca de sal). Por tanto, en este último caso, estamos ante una transferencia léxica que

\footnotetext{
20 Muy probablemente el informante 6 ha reconstruido la colocación gota de aceite sobre la base de conocimientos previos. Efectivamente, el sustantivo aceite también puede ser seleccionado por el acotador gota; sin embargo, la cantidad de líquido acotado será diferente a la que se indica con un chorro de aceite. De hecho, el sustantivo gota remite a una "pequeña porción de un líquido, con forma esferoidal" (DLE). Asimismo, los contextos y las finalidades de uso de las dos colocaciones varían notablemente; mientras que la colocación chorro de aceite se usa mayoritariamente en contextos culinarios, la construcción pseudopartitiva una (o más) gota(s) de aceite la encontraremos generalmente en contextos de cuidado personal, como apreciamos en "además del agua de color, le añadimos una gota de aceite esencial aromático" (CORPES XXI).
} 
tiene lugar desde una lengua extranjera, el inglés, a la lengua meta, el español, y no a partir de la lengua materna de los informantes ${ }^{21}$.

Una combinación que, en cambio, podemos adscribir a la categoría de la transferencia semántica es la de *hilo de aceite (en lugar de chorro / chorrito de aceite), formada por los informantes 5 (de nivel B2/C1) y 11 (de nivel C1), de nacionalidad brasileña y francesa, respectivamente. Como ya hemos visto anteriormente, la forma correspondiente a chorro de aceite en portugués es fio de azeite; asimismo, su equivalente en francés es filet d'huile. Esta transferencia se debe al hecho de que, cuando fio y filet no funcionan como sustantivos acotadores, sino que remiten a una "hebra larga y delgada de una materia textil, especialmente la que se usa para coser" (DLE), su forma correspondiente en español es hilo: hilo de algodón, fio de algodão y filet de coton. Hablamos de transferencia semántica, puesto que lo que se transfiere a la lengua meta no es una forma gráfica de una determinada lengua de origen (como en el caso de *fio de aceite), sino, más bien, el contenido semántico de fio y de filet. De hecho, los tres sustantivos proceden del latín filum y la imagen de un líquido cayendo de un recipiente con una apertura estrecha recuerda, por extensión, la de un hilo22.

Para explicar la etiqueta de no-separación conceptual, pensemos en el fenómeno lingüístico denominado por Cliffard Pastor split (esto es, separación, divergencia), al que nos hemos dedicado en el apartado 3. Haciendo memoria del concepto que encierra, el split consiste en la correspondencia de un elemento lingüístico dado (en nuestro caso, una unidad léxica) de una determinada lengua de origen a dos o más elementos lingüísticos (aquí, unidades léxicas) de la lengua meta. Si retomamos el texto de la receta, veremos que el primer y el tercer espacio requieren ser completados por sustantivos acotadores que, junto con la preposición en, forman locuciones adverbiales: 1) pelar y picar las cebollas en pelar las naranjas y cortarlas en de $1 \mathrm{~cm}$ de grosor. Asimismo, notaremos que el sustantivo que pedimos insertar en el tercer espacio deberá ser el mismo que aparecerá en el séptimo espacio, esta vez en función de colocado de la construcción pseudopartitiva resultante: 7) finalmente, añadir las __ de naranja a la fuente. Precisamente en estos tres espacios, aunque de forma heterogénea, cuatro informantes han colocado el sustantivo pieza en número plural (piezas), en lugar de rodajas o de los distintos sustantivos que remiten a la forma en la que se pueden cortar los alimentos (en dados, en tiras, etc.). A título de ejemplo, el informante 1 (de nivel C1/C2) -que ha alcanzado un resultado notable en las tres pruebas, sumando el $75 \%$ de las respuestas correctas- ha rellenado el segundo y el séptimo espacio con dicho sustantivo, formando construcciones como *en piezas ( ${ }^{*}$ cortar las naranjas en piezas) y *piezas de naranja. Como sabemos, en español el sustantivo pieza no hace referencia a una unidad acotada de un referente entero; en otras palabras, no indica una porción que se separa-por ejemplo, mediante un corte- de un referente alimenticio, sino que, en la acepción y en la función más cercanas a las que puede tener un sustantivo acotador, indica "cada uno de los

\footnotetext{
${ }^{21}$ Mientras que fio no forma parte del acervo léxico del español, el sustantivo pincha se registra en el DLE como forma masculina del sustantivo pinche, esto es 'ayudante de cocina'. De todas formas, en ningún caso estamos ante un sustantivo con función acotadora.

22 Nótese que en español el sustantivo hilo también puede tener función acotadora y seleccionar referentes líquidos; sin embargo, la forma de líquido acotada será más delgada que la del chorro.
} 
objetos que componen un conjunto; o cada unidad de ciertas cosas o productos que pertenecen a una misma especie" (DLE); de ahí que podamos decir frases como este juego de tazas tiene 12 piezas o es recomendable no comer más de 3 piezas de fruta al día. En la primera frase pieza remite a cada uno de los elementos, esto es, las tazas, que componen un juego de tazas y en la segunda frase a tres unidades (enteras) de fruta, es decir, a tres frutas y no a tres pedazos de fruta. A este respecto, cabe decir que, al ser la lengua materna del informante 1 el inglés, es muy probable que la confusión surja precisamente del hecho de que tanto pieza como pedazo (el acotador que sí forma la locución adverbial en pedazos y múltiples construcciones pseudopartitivas) correspondan al sustantivo del inglés piece ${ }^{23}$. Curiosamente, incluso los informantes 2, 3 y 4, de nacionalidad china y francesa, han utilizado el sustantivo pieza de la misma forma que el informante 1, muy probablemente por influencia del inglés.

\section{Conclusiones}

Después de un largo recorrido por las distintas clases de colocaciones «sustantivo + de + sustantivon, llegamos, por fin, a dar respuesta a nuestras preguntas de investigación. Como recordamos, la primera pregunta indaga sobre el conocimiento que tienen los estudiantes/hablantes de E/LE de niveles intermedios y avanzados acerca de este tipo de colocaciones, mientras que con la segunda pregunta nos proponemos averiguar si dicho conocimiento es proporcional al nivel general de español de los informantes, es decir, si conocen más colocaciones «sustantivo + de + sustantivo» los hablantes de niveles superiores que los de niveles intermedios.

Antes que nada, cabe decir que el número exiguo de informantes no nos permite dar respuestas estadísticamente significativas; por lo que nuestro interés se ha centrado más en datos de tipo cualitativo que cuantitativo.

Respecto a la primera pregunta, los resultados obtenidos en el test nos muestran que el conocimiento de las colocaciones objeto de estudio varía notablemente de individuo a individuo. Por una parte, encontramos informantes que han demostrado tener un dominio activo de los sustantivos cuantificativos -claramente visible en las pruebas 1 y $3-$ y proporcional al nivel que se han autodeterminado; por otra parte, observamos cómo algunos informantes que se consideran de nivel avanzado desconocen la mayoría de los cuantificativos presentes en el test y las combinaciones léxicas a las que pueden dar lugar.

Para contestar a la segunda pregunta, nos basamos en los porcentajes relativos a los resultados obtenidos por los informantes. Si bien, en línea general, observamos que los informantes que se han encuadrado en los niveles superiores C1/C2 (aquí

\footnotetext{
23 Como leemos en Oxford Advanced Learner's Dictionary, la primera acepción de piece remite a "an amount of something that has been cut or separated from the rest of it" (a piece of cake, a piece of cheese), esto es, a una porción de algo (una tarta, un queso, etc.) que ha sido cortada o separada del resto. En esta acepción piece funciona como sustantivo acotador y sus equivalentes más próximos en español son los sustantivos trozo y pedazo (un trozo de tarta, un pedazo de queso). En la cuarta acepción del mismo diccionario, en cambio, piece indica "a single item of a particular type, especially one that forms part of a set", es decir, una unidad (una pieza) de una determinada categoría, que, por lo general, forma parte de un conjunto; razón por la cual, en a 12-piece coffee set el sustantivo piece no tiene función acotadora y su equivalente en español es pieza (un juego de café de doce piezas).
} 
incluimos también los que se definen de B2/C1) han obtenido resultados mejores que los de niveles intermedios B1/B2, destaca el hecho de que algunos informantes, en concreto los números 2, 3 y 12, hayan alcanzado resultados significativamente bajos, formando correctamente solo una, dos y cuatro colocaciones respectivamente. Por tanto, podemos afirmar que el nivel de conocimiento que los informantes tienen de las colocaciones objeto de estudio no siempre es proporcional a su nivel general de español.

Haciendo un repaso de los errores cometidos por los informantes, notamos que el desconocimiento de las colocaciones usustantivo + de + sustantivo" se manifiesta a través de tres tipos diferentes de producciones lingüísticas:

1) Formación de una combinación léxica inexistente en la lengua meta, tanto por interferencia intralingüística (por ejemplo, *Ionchas de naranja sobre la base de la colocación lonchas de jamón) como por interferencia extralingüística (por ejemplo, *piezas de naranja a partir del inglés pieces of orange);

2) Uso de sustantivos acotadores de significado genérico y con un más amplio grado de colocabilidad en lugar de sustantivos que forman restricciones léxicas (trozos de ajo en lugar de dientes de ajo24);

3) Uso de construcciones pseudopartitivas (aceptadas en la lengua) formadas a partir de la locución adjetival un poco y de su forma diminutiva un poquito (un poco / poquito de sal en lugar de una pizca de sal) o de sustantivos que expresan medida aproximada (una cucharada de vinagre en lugar de un chorro / chorrito de vinagre).

Pasando a una consideración externa, cabe decir que las colocaciones "sustantivo + de + sustantivo», de modo especial, las que se construyen con sustantivos acotadores que seleccionan referentes alimenticios, se aprenden, por lo general, en ámbitos familiares o sociales, como la cocina. De hecho, los dos únicos informantes que nunca han vivido en un país hispanohablante han alcanzado algunas de las puntuaciones más bajas. De todos modos, incluso informantes que han estudiado español durante varios años y que han vivido o están viviendo en España, y que se consideran de nivel avanzado, han obtenido resultados significativamente más bajos que otros de nivel intermedio. De todo ello se desprende que la herramienta más eficaz para poder aprender estas colocaciones está en la enseñanza misma, es decir, en la introducción gradual y sistemática de los sustantivos cuantificativos en el aula de E/LE.

Nos acercamos al final de nuestro recorrido y aprovechamos nuestras últimas líneas para sugerir un método que nos ayude a introducir las colocaciones objeto de estudio en el aula. Como hemos visto a lo largo de este artículo, la mayoría de los sustantivos acotadores selecciona referentes alimenticios, mientras que los sustantivos de grupo se especializan en delimitar referentes animales. Asimismo, estos son los campos semánticos que se presentan a los alumnos a partir de los

\footnotetext{
${ }^{24}$ Como sabemos, la combinación léxica trozo de ajo es correcta en español, pero no equivale a diente de ajo, puesto que esta última remite a cada una de las porciones en las que se divide naturalmente el ajo. Al contrario, con trozos de ajo hacemos referencia a porciones de ajo cortadas artificialmente, por ejemplo, mediante un cuchillo.
} 
niveles iniciales A1/A2. Sin embargo, la información que se desprende de estas colocaciones requiere un considerable esfuerzo de procesamiento al que no podemos someter los alumnos de nivel principiante; razón por la cual sería conveniente delinear un programa didáctico que prevea introducirlas a partir del nivel intermedio Bl de forma gradual y sistemática acorde con las funciones comunicativas y los campos léxicos que vayamos presentando a los alumnos. Por tanto, la metodología didáctica que sugerimos aquí prevé volver a lo largo de las distintas fases de enseñanza-aprendizaje sobre los campos léxicos donde más abundan las colocaciones "sustantivo + de + sustantivo", el de la comida y el de los animales, con el fin de enseñar unidades léxicas nuevas y proporcionar más información acerca de las que se han introducido en los niveles anteriores; parte de esta información será relativa a los colocativos que se combinan con los sustantivos base ya conocidos. De todos modos, sería aconsejable que la enseñanza de los colocativos se llevara a cabo atendiendo a los criterios de frecuencia de uso y de inteligibilidad semántica; razón por la cual en el nivel Bl convendría limitarse a los sustantivos acotadores con significado recto que se usan más a menudo (como loncha y rebanada de la variedad peninsular) y solo una vez llegados al nivel B2, introducir los acotadores de significado metafórico que seleccionan referentes concretos (como diente en un diente de ajo). Finalmente, a partir del nivel $\mathrm{Cl}$ aconsejamos empezar a presentar los acotadores de significado metafórico que seleccionan sustantivos abstractos (como brizna en una brizna de esperanza).

En lo que atañe a los sustantivos cuantificativos de grupo, por usarse en menor medida con respecto a los acotadores y por suponer un esfuerzo cognitivo mayor, debido a las selecciones léxicas biunívocas entre la base y el colocativo, sería aconsejable empezar a introducirlos a partir del nivel B2.

Para concluir, el método que sugerimos aquí, y que nos proponemos desarrollar en investigaciones futuras, es el de enseñar las colocaciones «sustantivo + de + sustantivo»l de forma gradual y sistemática, empezando por la introducción de los sustantivos cuantificativos más productivos. Asimismo, para que el aprendizaje de los cuantificativos no sea sectorial, sería oportuno incorporar las construcciones pseudopartitivas a la enseñanza de aquellas unidades léxicas pluriverbales con las que guardan relaciones referenciales, como las locuciones adverbiales (en rodajas, en tiras).

\section{Bibliografía}

BARTOL HERNÁNDEZ, J. A. (2010): "Disponibilidad léxica y selección del vocabulario". De moneda nunca usada: Estudios dedicados a José $M^{a}$ Enguita Utrilla. Rosa M. CASTAÑER MARTíN \& V. LAGÜÉNS GRACIA (coords.), pp. 85-107. [Última consulta: 14 abril 2018]. Disponible en línea: https://ifc.dpz.es/recursos/publicaciones/29/95/09bartol.pdf

BARTSCH, S. (2004): Structural and Functional Properties of collocations in English. A corpus study of lexical and pragmatic constraints on lexical co-occurrence. Tubinga: Gunterr Narr Verlag. 
BOSQUE, I. (1999): "El nombre común". Gramática descriptiva de la lengua española (1): Sintaxis básica de las clases de palabras. I. Bosque \& V. Demonte(coords.). Madrid: Espasa Calpe. pp. 3-76.

BOSQUE, I. (dir.) (2006): Diccionario combinatorio práctico del español contemporáneo. Madrid: Ediciones SM.

BROWN, H. D. (1994)(1980): Principles of language learning and teaching. Englewood Cliffs, NJ: Prentice-Hall.

CORPAS PASTOR, G. (1996): Manual de fraseología española. Madrid: Gredos.

EVERT, S. (2008): "Corpora and collocations". Corpus Linguistics. An International Handbook. A. LÜDELING \& M. KYTÖ (eds.). Berlín: De Gruyter Mouton, pp. 12121248.

GARCÍA-PAGE SÁNCHEZ, M. (2008): Introducción a la fraseología española. Estudio de las locuciones. Barcelona: Antrophos.

HAMAWAND, Z. (2014): "Partitives: an exploration in cognitive grammar", International Journal of English Linguistics. Vol. 4(1), pp. 112-126 [Última consulta: 1 diciembre 2017]. Disponible en línea: http://www.ccsenet.org/journal/index.php/ijel/article/view/33732

KOIKE, K. (2001): Colocaciones léxicas en el español actual: estudio formal y léxicosemántico. Alcalá de Henares: Universidad de Alcalá y Universidad de Takushoku.

MOLINER, M. (2007): Diccionario de uso del español (DUE). Madrid: Gredos.

REAL ACADEMIA ESPAÑOLA. ASOCIACIÓN DE ACADEMIAS DE LA LENGUA ESPAÑOLA (2010): Nueva gramática de la lengua española. Morfología / Sintaxis 1. Madrid: Espasa

\section{Sitografía}

CAMBRIDGE UNIVERSITY PRESS, C2018. Cambridge Dictionary [Última consulta: 10 enero 2018].

<https://dictionary.cambridge.org/dictionary/english>

HOLA.COM [Consulta: 1 marzo 2018].

<https://www.hola.com/cocina/recetas/20180201 105448/pollo-naranja-anisestrellado/>

OXFORD UNIVERSITY PRESS, (C2018: Oxford Advanced Learner's Dictionary [Última consulta: 11 mayo 2018].

<https://www.oxfordlearnersdictionaries.com/>

PIXABAY, (c) 2018: [Última consulta: 25 abril 2018].

$<$ https://pixabay.com/es/>

REAL ACADEMIA ESPAÑOLA, Corpus de referencia del español actual. Banco de datos (CORPES XXI) [Última consulta: 10 mayo 2018].

$<$ http://www.rae.es>

REAL ACADEMIA ESPAÑOLA, C2018: Diccionario de la lengua española (DLE) [Última consulta: 15 mayo 2018].

<http://dle.rae.es/? $\mathrm{w}=$ diccionario $>$ 